\title{
Partitioning of dissolved iron and iron isotopes into soluble and colloidal phases along the GA03 GEOTRACES North Atlantic Transect
}

\author{
Jessica N. Fitzsimmons*1,2, Gonzalo G. Carrasco ${ }^{2}$, Jingfeng $\mathrm{Wu}^{3}$, Saeed Roshan ${ }^{3}$, Mariko Hatta $^{4}$, \\ Christopher I. Measures ${ }^{4}$, Tim M. Conway ${ }^{5}$, Seth G. John ${ }^{5}$, and Edward A. Boyle ${ }^{2}$
}

${ }^{1}$ MIT/WHOI Joint Program in Chemical Oceanography, Cambridge, MA 02142; 1-617-324-0283; jessfitz@mit.edu

${ }^{2}$ Department of Earth Atmospheric and Planetary Sciences, Massachusetts Institute of Technology, Cambridge, MA 02142; gcarrasc@mit.edu; eaboyle@mit.edu; 1-617-253-3388

${ }^{3}$ Rosenstiel School for Marine and Atmospheric Sciences, University of Miami, Miami, FL 33149; 1-305421-4714; jwu@rsmas.miami.edu

${ }^{4}$ School of Ocean and Earth Science and Technology, University of Hawai'i at Manoa, Honolulu, HI 96822; mhatta@hawaii.edu; chrism@soest.hawaii.edu; 1-808-956-8693

${ }^{5}$ Department of Earth and Ocean Sciences, University of South Carolina, Columbia, SC 29208; tconway@geol.sc.edu; sjohn@geol.sc.edu; 1-803-777-7052

* designates the corresponding author

\begin{abstract}
The size partitioning of dissolved $\mathrm{Fe}(\mathrm{dFe}<0.2 \mu \mathrm{m})$ into soluble $(\mathrm{sFe}<0.02 \mu \mathrm{m})$ and colloidal $(0.02 \mu \mathrm{m}<\mathrm{cFe}<0.2 \mu \mathrm{m})$ species was investigated at 28 stations along the GEOTRACES GA03 North Atlantic Transect. Upper ocean dFe size partitioning was highly variable with depth: $79 \pm 6 \%$ of aerosolderived surface $\mathrm{dFe}$ was maintained in the colloidal size fraction, while $\mathrm{cFe}$ disappeared completely at the deep chlorophyll maximum, presumably a result of preferential cFe biological uptake and/or scavenging. In the intermediate and deep ocean, however, $\mathrm{dFe}$ was evenly partitioned $\sim 50: 50 \%$ into $\mathrm{sFe}$ and $\mathrm{cFe}$ phases, which we hypothesize results from a "steady state" of dFe exchange reactions during and following remineralization including ligand exchange, sorption/desorption, and aggregation/disaggregation. There were only two exceptions to this constant partitioning in the intermediate/deep ocean. First, cFe dominated (82-96\%) at and downstream of the Mid-Atlantic Ridge hydrothermal system. Also, along Line $\mathrm{W}$ between Woods Hole and Bermuda the dFe partitioning
\end{abstract}


favored $\sim 60-80 \% \mathrm{cFe}$, with the excess $\mathrm{cFe}$ likely resulting from inorganic $\mathrm{cFe}$ inputs from the margin. Thus, in the North Atlantic Ocean we propose a new model of dFe size partitioning where a "steady state" of $\mathrm{dFe}$ exchange reactions during and following remineralization re-partitions intermediate and deep ocean $\mathrm{dFe}$ into constantly fractionated $\mathrm{sFe}$ and $\mathrm{cFe}$ pools, while in the upper ocean, downstream of the Mid-Atlantic Ridge, and along Line $\mathrm{W}, \mathrm{sFe}$ and $\mathrm{cFe}$ appear to cycle more independently, as either not enough time has passed to reach a new $\mathrm{dFe}$ exchange steady state or one of the dFe phases is non-labile to $\mathrm{dFe}$ exchange. This surface-subsurface decoupling model of North Atlantic dFe size partitioning is supported by $\mathrm{Fe}$ isotope ratio analyses of the $\mathrm{sFe}$ and $\mathrm{dFe}$ size fractions, which recorded isotopically heavy $\mathrm{sFe}\left(\delta^{56} \mathrm{Fe}\right.$ of +1.3 to $+1.5 \%$ o relative to $\mathrm{dFe}\left(\delta^{56} \mathrm{Fe} \sim+0.5 \%\right.$ o $)$ in the surface ocean where sFe and cFe cycle independently, and identical $\mathrm{sFe}$ and $\mathrm{dFe}$ isotope ratios below $250 \mathrm{~m}$ where $\mathrm{sFe}$ and $\mathrm{cFe}$ are constantly partitioned and exchanged.

\section{Acknowledgements}

We thank Pete Morton, Randie Bundy, Ana Aguilar-Islas, and Sara Rauschenberg for assistance sampling on the U.S. GEOTRACES GA03 cruises. We also thank the Co-Chief Scientists, Bill Jenkins and Greg Cutter, for their leadership on this expedition, as well as the officers and crew of the R/V Knorr, who made sailing on this cruise the very best it could be. We also owe much gratitude to Rick Kayser and Angela Rosenberg for assistance in the laboratories with measurements. J.N. Fitzsimmons was funded by a National Science Foundation Graduate Research Fellowship (NSF Award \#0645960) and the Center for Microbial Ocenaography: Research \& Education (NSF-OIA Award \#EF-0424599). Research funding was provided by the National Science Foundation to E.A. Boyle (OCE \#0926204 and OCE \#0926197), S.G. John (OCE \#1131387), J. Wu (OCE \#0927558), and C.I. Measures (OCE \#0928741 and OCE \#1137812).

\section{Introduction}

The international GEOTRACES program endeavors to determine the global distribution of trace elements and their isotopes while also constraining the fluxes and processes controlling these distributions. One of the highest priority elements investigated by GEOTRACES is dissolved iron (dFe), which is known to be an essential micronutrient for marine phytoplankton (Morel et al., 2003; Sunda, 2012). Fe(III), the thermodynamically favored oxidation state of dFe in the oxic ocean, is largely insoluble, causing dFe to exist at very low concentrations that are predicted to limit phytoplankton growth in nearly $40 \%$ of the surface ocean (Moore et al., 2002). Based on electrochemical data, organic Febinding ligands are thought to bind $>99.9 \%$ of marine $\mathrm{dFe}$ (Rue and Bruland, 1995), buffering its concentration above biologically limiting levels in many regions of the global ocean. However, assessing the chemical composition of individual marine dFe species has yet to be accomplished due to analytical challenges (Gledhill and Buck, 2012), and this has made it difficult to understand the chemical 
transformations involved in the conversion of Fe between source and sink. The identity and rates of these transformations remain one of the biggest unknowns in marine Fe biogeochemistry today.

One tool we can use to explore the form, composition, and cycling of dFe in the ocean is the size partitioning of dissolved Fe species. We know that dFe (here defined as $<0.2 \mu \mathrm{m}$ ) is composed of both soluble $(\mathrm{sFe}<0.02 \mu \mathrm{m})$ and colloidal $(0.02 \mu \mathrm{m}<\mathrm{cFe}<0.2 \mu \mathrm{m})$ size fractions, and the partitioning across both geographic locations and depths is highly variable, with colloids contributing $0-90 \%$ of the $\mathrm{dFe}$ phase (Bergquist et al., 2007; Fitzsimmons and Boyle, 2014b; Wu et al., 2001). Colloidal Fe comprises submicron Fe particles so small that they do not sink, and these colloids pass through the $0.2 \mu \mathrm{m}$ filter separating dissolved from particulate Fe. Soluble Fe, in contrast, comprises the smallest, often considered "truly dissolved" Fe species. Resolving this physical description of dFe size partitioning with the chemical composition of $\mathrm{dFe}$ is, however, a significant challenge.

Since nearly all $\mathrm{dFe}$ is assumed to be organically bound in the open ocean (Rue and Bruland, 1995), we can assume to a first degree that both $\mathrm{sFe}$ and cFe are organically bound. Very few studies directly measuring the chemical binding environment of Fe have been completed. Some energy dispersive spectroscopy measurements on colloids imaged by electron microscopy supported the hypothesis that marine colloidal Fe is organically bound, while estuarine and coastal colloidal Fe contain an inorganic colloidal Fe oxyhydroxide component not observed in the open ocean (Wells and Goldberg, 1992). However, recent studies have found exceptions to the first order assumption that $\mathrm{dFe}$ is organically bound. Using synchrotron technology, von der Heyden et al. (2012) found that colloidal and particulate Fe in the Southern Ocean surface layer had an inorganic magnetite component. While we will also consider the possibility of an inorganic colloidal Fe component, we will work from the primary assumption that both $\mathrm{sFe}$ and $\mathrm{cFe}$ are organically-bound, a hypothesis largely supported in the literature (Gledhill and Buck, 2012; Rue and Bruland, 1995; Wells and Goldberg, 1992).

The size partitioning of dFe affects marine Fe biogeochemistry in two important ways. First, cFe has been shown to have aggregated to colloidal size from smaller "granules" of soluble material (Wells and Goldberg, 1992); thus, cFe has been hypothesized to be an actively aggregating pool that links the soluble and particulate phases of Fe via initial sorption followed by successive aggregation (Honeyman and Santschi, 1989). Not only does this size partitioning have implications for the chemical composition of the $\mathrm{dFe}$ pool, but it also can impact the fate and lifetime of $\mathrm{dFe}$ in any given location, depending on the relative rates of sorption/desoprtion and aggregation/disaggregation between the various Fe size fractions. Secondly, the speciation of Fe has a direct impact on its bioavailability, with different phytoplankton species preferring different dFe forms (Hassler and Schoemann, 2009; Hutchins et al., 1999). While very few studies have assessed the bioavailability of dFe from various size fractions, the few existing studies have suggested that $\mathrm{sFe}$ is preferred, and cFe is only indirectly bioavailable after release into the sFe pool 
(Chen and Wang, 2001; Wang and Dei, 2003) or as a result of protozoan grazing (Barbeau et al., 1996). Only a few colloidal Fe forms have been found to be highly bioavailable, including Fe bound to exopolymeric saccharides (Hassler et al., 2011b). In contrast, inorganic Fe colloids (synthetic Fe oxyhydroxides) as small as 6-50 Fe atoms were not bioavailable to diatoms (Rich and Morel, 1990). If these studies are taken as representative of total dFe bioavailability in the open ocean, then an understanding of the dFe partitioning between soluble and colloidal phases is required in order to best assess dFe bioavailability.

In this paper, we describe the size partitioning of dFe between soluble and colloidal species across the U.S. GEOTRACES North Atlantic Transect (international GEOTRACES section GA03), and we compare this to previous studies of dFe size partitioning in the North Atlantic. Several papers exploring the size fractionation of $\mathrm{dFe}$ in the Atlantic have been published (see map of sampling locations in Fitzsimmons and Boyle, 2014a, and in Figure 1 for the North Atlantic), yet these studies show different patterns in different regions. First, Bergquist et al. (2007) reported that sFe concentrations in the central Atlantic were constant with depth at $\sim 0.35 \mathrm{nmol} / \mathrm{kg}$, while cFe concentrations were highly variable. They concluded that a dynamic colloidal phase controls $\mathrm{dFe}$ variability alongside relatively invariant $\mathrm{sFe}$. Then with increased spatial coverage in a similar region, Fitzsimmons and Boyle (2014b) found sFe to be much more variable than measured by Bergquist et al. (2007) and concluded that both sFe and cFe must play an active role in controlling dFe distributions.

The GA03 data presented here encompass the first full ocean-basin transect of dFe size partitioning ever obtained, with higher spatial and depth resolution than any prior study globally. This transect identifies the major $\mathrm{dFe}$ size fractions present across multiple water masses (surface currents, mode waters, Labrador Sea Water and Antarctic Intermediate Waters, and both North Atlantic Deep Water and Antarctic Bottom Water). It also characterizes the dFe size partitioning unique to four major $\mathrm{dFe}$ inputs in the North Atlantic: the North African dust flux to the surface ocean, the Mid-Atlantic Ridge hydrothermal plume, sedimentary resuspension along the western Atlantic margin, and the dFe maxima of Mauritanian oxygen minimum zone (OMZ). Our description of the dFe size patterns as a function of depth in the North Atlantic shows that most of the external Fe sources to the North Atlantic partition into the colloidal fraction, while biological/particle reactive processes near the deep chlorophyll maximum quantitatively remove colloidal Fe, and remineralization and the subsequent Fe exchange reactions balance the concentrations of $\mathrm{sFe}$ and $\mathrm{cFe}$ in the intermediate and deep oceans. We conclude with a synthetic model and discussion of the general size partitioning patterns of $\mathrm{dFe}$ in the North Atlantic Ocean, also using the Fe isotopic signature of the soluble and dissolved size fractions to corroborate our proposed model. 


\section{Methods}

\subsection{Sample Collection}

The size fractionation of $\mathrm{dFe}$ was determined at 28 stations in the North Atlantic Ocean aboard the R/V Knorr on the U.S. GEOTRACES North Atlantic Transect cruise (GA03; station locations in Figure 1). Sampling took place on two cruise legs: the 2010 cruise (USGT10), which sailed from Lisbon, Portugal, to Mindelo, Cape Verde Islands, from 14 October to 4 November, 2010, and the 2011 cruise (USGT11), which sailed from Woods Hole, Massachusetts, to Praia, Cape Verde Islands, from 6 November to 11 December, 2011. In order to keep the station names from these two cruises distinct, we refer to stations from the 2010 cruise as USGT10-xx, and from the 2011 cruise as USGT11-xx, where "xx" is the two-digit station number. All sample handling was completed in ISO 5-rated flow benches or clean rooms. Ultrapure water used in this study was first de-ionized by reverse osmosis, then purified through a Barnstead ultrapure deionizing cartridge, and finally distilled in a Corning vycor still. Unless otherwise indicated, all ultraclean hydrochloric $(\mathrm{HCl}, 6 \mathrm{M})$ acid used for cleaning, filtration, and acidification was obtained by four consecutive distillations of reagent grade $\mathrm{HCl}$ in a vycor still. This $\mathrm{HCl}$ was verified to have low Fe blanks $(\sim 0.1 \mathrm{nmol} / \mathrm{kg})$ by ICP-MS analysis after evaporation to dryness and a 10x pre-concentration in dilute nitric acid.

Clean seawater was collected using the U.S. GEOTRACES GO-FLO rosette by the methods described by Cutter and Bruland (2012). After rosette recovery, GO-FLO bottles were carried individually into an ISO 5-rated clean van, where the seawater was filtered through $0.2 \mu \mathrm{m}$ Pall Acropak$200^{\mathrm{TM}}$ Supor ${ }^{\circledR}$ capsule filters under $\sim 0.4$ atm of HEPA-filtered air. Filtration protocols were identical to those described by Fitzsimmons and Boyle (2012), except that the Acropak filters were pre-cleaned by soaking overnight in filtered surface seawater acidified to $\mathrm{pH} 2$ with clean $\mathrm{HCl}$, after which they were flushed with $5 \mathrm{~L}$ of unacidified $0.2 \mu \mathrm{m}$-filtered surface seawater and stored empty in the refrigerator until use. Surface seawater was collected using the GeoFish system, which employed PFA tubing attached to a vane that coasted at $\sim 3 \mathrm{~m}$ depth, suspended from a boom off the starboard side of the ship during forward motion at ship speeds up to 12 knots. An all-PFA diaphragm pump sipped clean surface seawater through this system at $\sim 0.5 \mathrm{~atm}$ pressure, passing first through a $0.45 \mu \mathrm{m}$ Osmonics (PFA) filter and then through a $0.2 \mu \mathrm{m}$ polycarbonate track-etched (PCTE) filter mesh housed in a polypropylene holder. Surface GeoFish and GO-FLO $<0.2 \mu \mathrm{m}$ filtrates for dFe analyses were collected in 1L LDPE bottles and acidified to $\mathrm{pH} 2$ with Seastar $12 \mathrm{~N} \mathrm{HCl}$ (containing $<0.09 \mathrm{nmol} / \mathrm{kg} \mathrm{Fe}$ ) onboard the ship within 2 days of collection. Additional $<0.2 \mu \mathrm{m}$ filtrates for further sFe ultrafiltration were first collected into $500 \mathrm{~mL}$ HDPE bottles after three bottle rinses, followed by secondary ultrafiltration as described below.

A different $\mathrm{sFe}: \mathrm{cFe}$ ultrafiltration method was used on each of the two cruises, and these two methods are described, summarized, and compared in Fitzsimmons and Boyle (2014a). In 2010, a cross 
flow filtration (CFF) technique using a Millipore Pellicon XL (PLCGC) regenerated cellulose membrane with a $10 \mathrm{kDa}$ nominal molecular weight cutoff (Pellicon) was used in static mode to collect sFe samples after system conditioning using 300-350mL of sample seawater. In 2011, $47 \mathrm{~mm}$ Anopore membrane filters made of alumina with $0.02 \mu \mathrm{m}$ pores were utilized on an offline, fluorocarbon filter rig (Savillex) to collect $\mathrm{sFe}$ samples after the filters were rinsed with $>50 \mathrm{~mL}$ of $\mathrm{pH} 1.5 \mathrm{HCl},>50 \mathrm{~mL}$ of ultrapure water, and $>50 \mathrm{~mL}$ of sample seawater. All sFe samples were acidified to $\mathrm{pH} 2$ with vycor-distilled $6 \mathrm{M}$ $\mathrm{HCl}$. Using these operational size-cutoffs, dFe is defined in this paper as $\mathrm{Fe}<0.2 \mu \mathrm{m}, \mathrm{sFe}$ is defined as $\mathrm{Fe}$ $<0.02 \mu \mathrm{m}$ (Anopore) or $<10 \mathrm{kDa}$ (CFF), and $\mathrm{cFe}$ is calculated as $\mathrm{dFe}$ minus sFe. These size definitions directly influence the interpretation of the data, since the use of Anopore filters assigns the $10 \mathrm{kDa}-0.02$ $\mu \mathrm{m}$ dFe compounds as sFe (USGT11 samples), while the $10 \mathrm{kDa}-0.02 \mu \mathrm{m}$ size fraction is assigned as cFe using CFF (USGT10 samples). In a previous intercalibration effort the average sFe through the CFF system was only $68 \pm 23 \%$ of that passing through the Anopore filters ( $n=23$ depths from the North Atlantic and Pacific Oceans), indicating that CFF has a smaller nominal pore size overall. Any comparison of sFe passing through both filter types is ultimately influenced by the natural spatial variability of the $10 \mathrm{kDa}-0.02 \mu \mathrm{m}$ size distribution and thus will vary spatially (Fitzsimmons and Boyle, 2014a).

Both $\mathrm{dFe}$ and $\mathrm{sFe}$ samples were also collected for $\mathrm{dFe}$ stable isotope ratio analysis on the USGT11 cruise at several stations: four depths at station USGT11-11, the surface of station USGT11-21, and one depth at station USGT11-23. In each case, $0.2 \mu \mathrm{m}$ filtered seawater was collected in 4 L LDPE bottles by the methods described above. $1 \mathrm{~L}$ of this was poured off into a $2 \mathrm{~L}$ HDPE bottle for dFe isotope ratio analysis and acidified to $\mathrm{pH} 2$ with vycor-distilled $6 \mathrm{M} \mathrm{HCl}$. The rest was ultrafiltered through the CFF system following 500 mL CFF system conditioning with sample seawater, followed by collection of $\sim 1 \mathrm{~L}$ of permeate ( $\mathrm{sFe}$ ) into a $2 \mathrm{~L} \mathrm{HDPE}$ bottle and acidification to $\mathrm{pH} 2$ with vycor-distilled $6 \mathrm{M} \mathrm{HCl}$. CFF was chosen over Anopore filtration for the ultrafiltration because of the faster filtration times facilitated by CFF for large volumes (Fitzsimmons and Boyle, 2014a).

\subsection{Analytical methods}

$\mathrm{dFe}(<0.2 \mu \mathrm{m})$ samples were analyzed in the Wu laboratory at the RSMAS at the University of Miami on a Thermo Neptune multi-collector ICP-MS using the isotope dilution and magnesium coprecipitation methods described in $\mathrm{Wu}$ and Boyle (1998). $\mathrm{sFe}(<0.02 \mu \mathrm{m})$ samples were analyzed in triplicate in the Boyle laboratory at MIT by isotope dilution MC-ICP-MS on a hexapole collision cell IsoProbe ICP-MS (Lee et al., 2011). This method employs an ${ }^{54} \mathrm{Fe}$-spike and batch pre-concentration with nitrilotriacetate resin (NTA Superflow ${ }^{\circledR}$, Qiagen). Fe procedure blanks and reported detection limits for both methods are shown in Table 1, along with comprehensive lab analyses of SAFe standard reference 
materials. The measured dFe concentrations in the SAFe reference samples are shown to be consistent with consensus values, indicating the high integrity of the Fe analyses reported here.

$\mathrm{dFe}$ and sFe stable isotope ratio analyses were conducted in the MTEL and CEMS laboratories at the University of South Carolina following the methods described in Conway et al. (2013). This method involves addition of a ${ }^{57} \mathrm{Fe}-{ }^{58} \mathrm{Fe}$ double spike in a 1:2 sample to spike ratio, batch pre-concentration onto Nobias PA-1 chelating resin, and purification for Fe by anion-exchange chromatography with AGMP-1 resin. Purified samples were analyzed using a Thermo Neptune MC-ICP-MS in high-resolution mode, with a jet interface and APEX-Q (ESI) desolvation system without membrane. Isobaric interferences from $\mathrm{Ni}$ and $\mathrm{Cr}$ were corrected by monitoring ${ }^{60} \mathrm{Ni}$ and ${ }^{53} \mathrm{Cr}$. Stable $\mathrm{Fe}$ isotope ratios were calculated using a data reduction scheme following the iterative method of Siebert et al. (2001), and are reported as $\delta^{56} \mathrm{Fe}$ in standard delta notation (\%o) relative to the IRMM-014 isotope standard. It has been shown (Conway et al., 2013; John, 2012) that the uncertainty on stable isotope measurements using this technique is dominated by internal analytical error, and so all uncertainties are expressed based on $2 \sigma$ standard internal error of samples and standards.

\section{Results and Discussion}

The distribution of $\mathrm{dFe}$ and the measured partitioning into soluble and colloidal phases across the transect are shown in Figure 2, and all $\mathrm{dFe}$ and sFe data are tabulated in the Supplementary Material and also along with all cruise data online at the Biological and Chemical Oceanography Data Management Office (BCO-DMO: http://www.bco-dmo.org/project/2066) under the project "U.S. GEOTRACES North Atlantic Transect." An assessment of North Atlantic dFe biogeochemical cycling, in light of previous studies and general North Atlantic hydrography, is the subject of a companion paper (Hatta et al., this issue); however, the major hydrographic sections and a temperature-salinity diagram summarizing the major water masses of this section are included in the Supplementary Material accompanying this paper. The major Fe sources along GA03 are summarized below and can be inferred from Figure 2a.

The most noticeable feature of the GA03 dFe distribution is the hotspot of up to $\sim 68 \mathrm{nmol} / \mathrm{kg}$ that is observed at 3000-3500m at USGT11-16, which is attributable to the TAG (Trans-Atlantic Geotraverse) hydrothermal vent field centered at $26^{\circ} 8.2^{\prime} \mathrm{N}$ along the Mid-Atlantic Ridge (Rona et al., 1986), which contains black smoker vents known to consistently source fluids containing $\sim 5 \mathrm{mM}$ Fe into the abyssal ocean (Chiba et al., 2001). Additionally, in the surface ocean (Figure 3) dFe enrichments in excess of 1 $\mathrm{nmol} / \mathrm{kg}$ are attributed to the solubilization of aerosol Fe blown in from continental sources predominantly from the North African continent but also from North America and Europe. Finally, there appear to be dFe maxima emanating from both margins at intermediate depths. The western margin dFe maximum from 1000-2500 $\mathrm{m}$ in excess of $1 \mathrm{nmol} / \mathrm{kg}$ corresponds to the depth range of Labrador Sea 
Water (LSW, as defined by Jenkins et al., this issue), extending across the western boundary to the Bermuda Atlantic Time Series (BATS) station (USGT11-10). The eastern dFe maximum, also in excess of $1 \mathrm{nmol} / \mathrm{kg}$, is coincident with the Mauritanian $\mathrm{OMZ}$ and is not thought to derive from a margin Fe source but rather from remineralization of high Fe:C organic material (Fitzsimmons et al., 2013; Wu et al., this issue).

This Results \& Discussion section is organized as follows. In section 3.1, we present and discuss the major patterns of dFe size partitioning in the North Atlantic as a function of depth (surface, deep chlorophyll maximum, and intermediate/deep ocean) and region (west, central, and east Atlantic). In Section 3.2, we propose a synthesis model of dFe size partitioning in the North Atlantic that allows a consensus between the results of this study and all other published studies of dFe size partitioning in the North Atlantic. In Section 3.3, we present the Fe isotope ratios of sFe and $\mathrm{dFe}$ in the North Atlantic, and we discuss how these data support our synthesis model of dFe size partitioning. We conclude in Section 3.4 with a discussion of the open questions concerning marine dFe physicochemical state.

\section{1 dFe size partitioning results}

\subsubsection{Surface ocean}

The southern portion of the North Atlantic Ocean is directly downwind of North African dust sources and is thus expected to receive one of the highest dust loadings on the planet (Jickells et al., 2005). As 3.5\% of dust by weight is composed of Fe (Taylor and McLennan, 1985), high dust loadings and subsequent dust solubilization should result in high Fe inputs to the surface ocean, and accordingly there are several reports of elevated surface dFe concentrations in the North Atlantic (Bergquist and Boyle, 2006; Croot et al., 2004; Fitzsimmons et al., 2013; Measures et al., 2008; Rijkenberg et al., 2008; Rijkenberg et al., 2012). On GA03, both total aerosol Fe loading and the Fe solubility varied over more than an order of magnitude across the four aerosol end-members (North Africa, North America, Europe, and "marine"), with the highest Fe loading but lowest Fe solubility deriving from North African sources (Shelley et al., this issue). Thus, high surface dFe concentrations over much of GA03 were expected, and elevated surface ocean dFe concentrations $\geq 1.0 \mathrm{nmol} / \mathrm{kg}$ during GA03 were in fact observed (Figure 3; Hatta et al., this issue).

Despite the surface enrichment of $\mathrm{dFe}, \mathrm{sFe}$ occurred at very low concentrations averaging $0.16 \pm 0.05 \mathrm{nmol} / \mathrm{kg}$ during USGT11 (Figure 3, also expanded in Supplementary Material Figure S3), while the colloidal contribution to $\mathrm{dFe}$ (hereafter referred to as $\% \mathrm{cFe}$ ) dominated at $79 \pm 6 \%$. This high colloidal contribution is the same within error as the $80 \pm 7 \% \mathrm{cFe}$ determined from six stations in the tropical North Atlantic (Fitzsimmons and Boyle, 2014b; station locations shown in Figure 1) and thus appears to be representative of $\mathrm{dFe}$ size partitioning in the tropical and subtropical surface Atlantic 
underlying the North African dust plume. Aerosol-solubilized Fe seems to be preferentially maintained in the colloidal size fraction, which has been observed previously by others (Bergquist et al., 2007;

Fitzsimmons and Boyle, 2014b; Wu et al., 2001), while lower dust regions such as the Subarctic Pacific (Nishioka et al., 2001b) and Southern Ocean (Boye et al., 2010) do not show these cFe surface maxima.

It is possible that aerosol $\mathrm{Fe}$ is predominantly released into the colloidal size fraction, which would directly explain the observed surface cFe maxima. Alternatively, aerosol Fe could be released as both $\mathrm{sFe}$ and $\mathrm{cFe}$, after which most of the $\mathrm{sFe}$ is taken up rapidly by microorganisms, leaving only $\mathrm{cFe}$ in the mixed layer. Another possibility is that $\mathrm{sFe}$ addition exceeds organic complexation capacity (or does not react with organics on relevant timescales) and thus is converted or aggregated into inorganic colloids. If there was an aerosol-derived sFe component, enhanced surface sFe might have been expected somewhere along our cruise track, given the variability in surface primary production from the gyre to the upwelling region along Mauritania; however, surface sFe was $\leq 0.22 \mathrm{nmol} / \mathrm{kg}$ at all stations except USGT10-07. This might suggest that the first hypothesis of direct aerosol Fe solubilization into the colloidal size fraction is more likely. Lab-based aerosol leaching experiments are consistent with aerosol Fe release directly into the colloidal-sized dFe pool (Aguilar-Islas et al., 2010), although one should be concerned whether excess Fe binding ligands are saturated during these experiments, which would generate colloidal Fe oxyhydroxides and bias the resulting dFe size observed. Our data cannot resolve whether dust-derived Fe is deposited directly into the soluble or colloidal size fractions but simply indicate that $\mathrm{cFe}$ always ends up dominating much of the aerosol-derived dFe surface maximum. Finally, it is also worth noting that dFe size partitioning at USGT11-02, which receives aerosol inputs derived from anthropogenic North American sources (as determined by Shelley et al., this issue), shows the same surface $\mathrm{dFe}$ partitioning into the colloidal phase as stations receiving $\mathrm{dFe}$ inputs from North African desert aerosols.

The observed dust-derived surface cFe maxima could have any of three possible chemical compositions: 1) Fe bound by colloidal-sized organic ligands after solubilization from dust, oxidation of photochemically-produced Fe(II), and/or biological cycling, 2) colloidal-sized pieces of dust that physically eroded from the aerosol particles upon impact with the surface ocean (resulting in a dust-like, inorganic cFe composition), or 3) sFe that was released initially from dust in the surface ocean but then re-precipitated in situ (also resulting in an inorganic cFe composition, likely amorphous Fe oxyhydroxides). Whichever of these three Fe forms composes the surface colloidal Fe pool has important implications for $\mathrm{dFe}$ availability to phytoplankton and thus Fe's influence on the carbon cycle. Organically-bound cFe species may be bioavailable, either directly (Hassler et al., 2011a; Hassler et al., 2011b) or after solubilization through the sFe phase (Chen et al., 2003; Chen and Wang, 2001; Wang and Dei, 2003). However, inorganic cFe of Fe-oxyhydroxide (Rich and Morel, 1990) or Fe-silicate 
composition is not thought to be bioavailable. A large inorganic component of surface cFe could significantly change our understanding of the bioavailability of this dFe pool and warrants further study. We will return to the question of cFe chemical composition in Section 3.4 below.

\subsubsection{Deep chlorophyll maximum (DCM)}

Several profiles of $\mathrm{sFe}$ and $\mathrm{cFe}$ in the tropical and subtropical North Atlantic have demonstrated cFe minima in the deep chlorophyll maxima (DCM) (Bergquist et al., 2007; Fitzsimmons and Boyle, 2014b; Ussher et al., 2010). Similarly, along GA03 we found that at most stations cFe reached a minimum in the DCM, and at many stations DCM cFe disappeared completely (Figure 4). An exception to this was the western margin Line $\mathrm{W}$ transect (Figure 4a), where cFe was high throughout the upper ocean, presumably reflecting an external margin source of cFe (see Section 3.1.3.3). However, at most open ocean stations cFe disappeared completely at the DCM (Figure 4b-e), even along the more northern stations of USGT10 nearer to Europe (Figure 4d, USGT10-05 example shown). We suggest several possible explanations for the absence of $\mathrm{cFe}$ in the DCM:

(1) Colloidal Fe is bioavailable and is preferably taken up by microorganisms over sFe in the DCM. Experimental studies have suggested that sFe is biologically preferred over cFe (Chen et al., 2003; Chen and Wang, 2001; Wang and Dei, 2003), especially when the cFe occurs in inorganic forms such as oxyhydroxides (Rich and Morel, 1990). However, some forms of cFe may be utilized by microorganisms, and if this cFe was taken up preferentially over sFe in the DCM, an absence of cFe in the DCM might be expected. A controlled ecosystem enclosure experiment by Nishioka et al. (2001a) showed that cFe decreased the most out of all $\mathrm{dFe}$ size fractions during a simulated phytoplankton bloom, some of which was attributed to biological uptake of $\mathrm{cFe}$ species (although also to $\mathrm{cFe}$ aggregation). Additionally, studies of Fe bound to colloidal-sized exopolymeric saccharides (EPS) found Fe-EPS to be highly bioavailable (Hassler et al., 2011a; Hassler et al., 2011b), supporting the hypothesis that some cFe may be biologically utilized by organisms in the DCM. Moreover, phytoplankton living in the light-limited DCM have higher cellular Fe requirements (Sunda and Huntsman, 1997) that could encourage their more aggressive utilization of any $\mathrm{dFe}$ phase available, including $\mathrm{cFe}$, which might further explain a DCM-specific minimum in $\mathrm{cFe}$.

\section{(2) Colloidal Fe is scavenged and/or aggregated to the particulate phase in the DCM. Because} colloidal aggregation rates have been modeled as a second order reaction with respect to particle concentration (Stumm and Morgan, 1996), then when the number of particles increases in the DCM, aggregation rates should increase as well and could aggregate all of the colloidal Fe into particulate $\mathrm{Fe}$ phase in this layer. While it is well known that the fluorescence maximum designated as the DCM does not necessarily indicate a biomass maximum (Taguchi et al., 1988), we compared the fluorescence trace 
used to derive the depth of the DCM to the light transmission trace, which indicates depths with higher particulate loadings. As the example shown in Figure 4f shows, at many stations the DCM depth did match the depth of minimum light transmission, indicating that the DCM is the relative particle maximum that would be expected to promote increased $\mathrm{cFe}$ aggregation rates that favor the formation of particulate $\mathrm{Fe}(\mathrm{pFe})$. We must note, however, that $\mathrm{pFe}(>0.45 \mu \mathrm{m})$ concentrations also reach a relative minimum at the DCM (Ohnemus and Lam, this issue), which might not be expected if $\mathrm{dFe}$ was being converted into $\mathrm{pFe}$ at these depths. However, low DCM pFe may occur because these particles are large enough to experience gravitational forcing and, thus, may sink quickly out of the DCM. Ohnemus and Lam (this issue) successfully modeled how a DCM pFe minimum results when dust-derived $\mathrm{pFe}$ is incorporated into large aggregates in the mixed layer and sink through the DCM to disaggregate below, resulting in low $\mathrm{pFe}$ in the DCM. This same model could extend to dust-derived $\mathrm{cFe}$ and explain the cFe minimum at the DCM. Importantly, this pattern only results when the DCM occurs below the mixed layer depth, which excludes Line W stations where accordingly there was no DCM cFe minimum observed (Figure 4a).

(3) A unique Fe-ligand partitioning pattern in the DCM with an absence of colloidal ligands or a low concentration of anomalously weak colloidal ligands favors the formation of soluble-sized Fe-ligand compounds at the DCM. The current consensus based on electrochemical measurements of seawater is that nearly all marine dissolved $\mathrm{Fe}$ is bound by both strong and weak organic Fe-binding ligands (Gledhill and Buck, 2012; Rue and Bruland, 1995; van den Berg, 1995; Wu and Luther, 1995). Thus, at equilibrium the concentrations and strengths of the ligands in the soluble and colloidal size fractions should directly determine the observed size partitioning of $\mathrm{dFe}$. If the DCM had no colloidal ligands or soluble ligands were significantly stronger there, we might expect organically bound $\mathrm{dFe}$ to fall more in the soluble size fraction at the DCM. To date there are only three studies containing size fractionated Fe ligand data (Boye et al., 2010; Cullen et al., 2006; Thuróczy et al., 2010), and none have sufficient depth resolution to capture the DCM. The few size-fractionated Fe-ligand samples collected on GA03 are the subject of another paper (Fitzsimmons et al., in press) but show a predominance of soluble-sized Fe ligands throughout the entire upper ocean with no large change in ligand partitioning at the DCM. Thus, the existing data do not support this hypothesis that ligand partitioning produces a unique $\mathrm{dFe}$ size partitioning at the DCM.

It is also important to note that while cFe concentrations were quite variable in the upper ocean, sFe was nearly constant from the surface through the DCM at concentrations of $0.05-0.20 \mathrm{nmol} / \mathrm{kg}$ (Figure 4). Additionally, sFe was never depleted to zero concentration in the euphotic zone, which might be expected if it was the more bioavailable fraction (Chen et al., 2003; Chen and Wang, 2001; Rich and Morel, 1990; Wang and Dei, 2003). Fitzsimmons and Boyle (2014b) hypothesized that this persistent sFe 
fraction might be relatively more refractory, potentially bound by ligands so strongly that the $\mathrm{Fe}$ is not biologically accessible. An alternate explanation is that this $\mathrm{sFe}$ is so labile that we are measuring a pseudo-"steady state" sFe concentration that is biologically/photochemically cycled so rapidly that it is never fully depleted. Up to $50 \%$ of the $\mathrm{dFe}$ in the western subarctic Pacific was found to be composed of $\mathrm{Fe}(\mathrm{II})$ at mid-day (Roy et al., 2008), but we do not know which size fraction of dFe this Fe(II) would comprise. Free Fe(II) would fall in the soluble size fraction, but if marine Fe(II) were ligand bound, it could be either soluble or colloidal. Marine Fe(II) has only been hypothesized to be bound by organic ligands (Roy and Wells, 2011), but experiments suggest that Fe(II) in rainwater is ligand-bound (Kieber et al., 2005; Willey et al., 2008). Notably, the surface sFe concentrations across GA03 were very similar

to $\mathrm{Fe}(\mathrm{II})$ concentrations measured by Sedwick et al. (this issue), despite the very different methods used to measure these two concentrations, and thus Fe(II) may compose a portion of the sFe pool. However, there is no evidence precluding a colloidal Fe(II) fraction. Unfortunately, too few surface samples were collected at night to fully resolve a day-night cycle in surface dFe size fractionation, and thus the relative impact of biology/photochemistry on the sFe persistence could not be determined.

\subsubsection{Intermediate and deep ocean}

The intermediate and deep ocean dFe distribution and relative size partitioning can be seen in Figure $2 \mathrm{a}$ and is discussed relative to circulation and major subsurface dFe sources in Hatta et al. (this issue). Here, we discuss first in section 3.1.3.1 the subsurface dFe partitioning away from external Fe sources, with a goal of identifying the influence of remineralization and deep ocean circulation on the size fractionation of subsurface dFe. In addition to remineralization, it is clear that the North American and North African margins and the Mid-Atlantic Ridge supply dFe to the deep ocean (Figure 2), potentially with uniquely partitioned dFe signatures. We discuss the effects of those Fe sources in section 3.1.3.23.1.3.4. Although we have included a T-S diagram in the Supplementary Materials that summarizes the major water masses of GA03, we predominantly use the intermediate and deep ocean water masses defined by an Optimum Multi Parameter Analysis (OMPA) applied by Jenkins et al. (this issue) along the entire GA03 cruise transect. Importantly, each water mass in this model was defined using a suite of conservative water mass properties from "proximal" locations to GA03 rather than from the formation regions of the water masses. This must be kept in mind when quantitatively estimating the end-member contributions of non-conservative species, such as dFe.

\subsubsection{Non-margin deep ocean \& remineralization effects}

Intermediate and deep ocean waters of the North Atlantic away from the margins and the MidAtlantic Ridge (MAR) had a very reproducible dFe distribution and size partitioning. In intermediate 
waters (DCM through $\sim 1000 \mathrm{~m}$ ), dFe concentrations were low, ranging from $\sim 0.2-0.5 \mathrm{nmol} / \mathrm{kg} \mathrm{Fe}$, with higher concentrations on the western and eastern margins (Figure 2, Hatta et al., this issue). Both sFe and cFe were also very low $(\leq 0.2 \mathrm{nmol} / \mathrm{kg})$ at intermediate depths, and each contributed about $50 \%$ of the $\mathrm{dFe}$. Away from the margins, these intermediate waters were dominated by North Atlantic Central Water, Antarctic Intermediate Water, Irminger Sea Water, and Mediterranean Outflow Water. In the deep waters below $1000 \mathrm{~m} \mathrm{dFe}$ was typically $\geq 0.6 \mathrm{nmol} / \mathrm{kg}$, except in the deepest samples of station 12 and station 22 where $\mathrm{dFe}$ dropped below $0.5 \mathrm{nmol} / \mathrm{kg}$ (at these stations, Antarctic Bottom Water, AABW, contributed $\geq 40 \%$, as defined by Jenkins et al., this issue). $\mathrm{sFe}$ and cFe concentrations in these deep waters were nearly equal at $\sim 0.3 \mathrm{nmol} / \mathrm{kg}$ each, except in the $\mathrm{AABW}$-impacted regions where $\mathrm{cFe}$ was depleted to $\leq 0.2 \mathrm{nmol} / \mathrm{kg}$. The sFe:cFe partitioning in intermediate and deep waters was very similar at $\sim 50: 50 \%$ (white hues in Figure 2d). Exceptions to this include the sFe excess in AABW-influenced regions, a slight trend towards excess $\mathrm{sFe}$ near $\sim 1000 \mathrm{~m}$ depth, and a clear cFe excess in Line W stations (USGT11-02 through USGT11-10).

Traditionally, deep ocean dFe is believed to arise from remineralization (Johnson et al., 1997). Thus, in order to assess the influence of remineralization on dFe partitioning, we examined the relationship between $\mathrm{dFe}$ species and the apparent oxygen utilization (AOU), which is a measure of the integrated oxygen loss due to remineralization in a water parcel since it was last in contact with the atmosphere. We completed Type-I regressions between $\mathrm{AOU}$ and $\mathrm{dFe}, \mathrm{sFe}$, or cFe in the oxycline (Figure 5, oxygen section in Figure S1d), which happens to fall in the Central Water layer (potential density 25.827.1, which corresponds to $\sim 100-600 \mathrm{~m}$ depth, see Figure S1c potential density section). In order to avoid the influence of external Fe sources on our dFe regressions, we followed Hatta et al. (this issue) and eliminated USGT11-02 (influenced by North American margin dFe inputs), the hydrothermally affected portions of USGT11-14 and USGT11-16, and stations USGT10-09 and USGT10-10, which are hypothesized to receive African margin Fe inputs, from these regressions to evolve the remineralizationonly dFe size partitioning pattern. We also subdivided the remaining stations of our transect into three regions: Line W (a), the subtropical gyre (b), and the margin-unaffected 2010 stations (c). Finally, the resulting Fe:AOU slopes were converted to Fe:C slopes using an AOU:C ratio of 1.6 (Martin et al., 1987), as in previous studies of dFe biogeochemistry in the North Atlantic (Bergquist and Boyle, 2006; Fitzsimmons et al., 2013). The Fe:C (slope) and pre-formed Fe (y-intercept) for both $\mathrm{dFe}$ and sFe are tabulated in Table 2.

The strong relationship between AOU and all three dFe size fractions (Figure 5) implies that the $\mathrm{dFe}$ size partitioning observed in the intermediate and deep North Atlantic Ocean results directly from remineralization or any subsequent $\mathrm{Fe}$ exchange/scavenging reactions following remineralization. The $\mathrm{sFe}: \mathrm{C}$ and $\mathrm{cFe}: \mathrm{C}$ all fall within error of each other (Table 2), explaining to a first order why the average 
partitioning is split 50:50\% sFe:cFe across much of GA03 (white in Figure 2d). We also note that this average 50:50\% partitioning is set by the $0.02 \mu \mathrm{m}$ filter used on the 2011 cruise. If a smaller pore size filter was utilized, such as the $10 \mathrm{kDa}$ filter on the 2010 cruise, a partitioning favoring more $\mathrm{cFe}$ might be expected. Following this, while not statistically significant because of the large standard errors for the regressions, the sFe:C ratio for the 2010 non-margin stations $(2.26 \pm 1.20 \mu \mathrm{mol} / \mathrm{mol})$ was lower than that of the nearby gyre stations $(2.83 \pm 0.36 \mu \mathrm{mol} / \mathrm{mol})$, which may to some extent reflect the smaller pore size (10 $\mathrm{kDa})$ used on the 2010 cruise compared to the 2011 cruise $(0.02 \mu \mathrm{m})$.

At intermediate depths, dFe must either be pre-formed or delivered by remineralization, where pre-formed $\mathrm{dFe}$ is defined here as the $\mathrm{dFe}$ that was present when the water was last at the surface and/or the $\mathrm{dFe}$ that has been added to the water parcel by processes other than remineralization before it reached the sampling site. We aimed to distinguish how much of the 50:50\% sFe:cFe partitioning arose from remineralization and how much resulted from the partitioning of pre-formed $\mathrm{dFe}$, working from a starting assumption that these Fe pools do not exchange rapidly. Thus, we calculated the ratio of sFe:C to dFe:C, which is tabulated in Table 2 as $\% \mathrm{sFe}_{\mathrm{REMIN}}$, to indicate the fraction of $\mathrm{dFe}$ that is partitioned into the soluble phase via remineralization, since any "pre-formed" Fe (the y-intercept of the Fe:AOU plot) is not included in this ratio calculated from the slopes. It is important to note that we constrained this calculation to a narrow water mass band (potential density $25.8-27.1 \mathrm{~kg} / \mathrm{m}^{3}$, mostly NACW), within which we assume that pre-formed $\mathrm{Fe}$ is identical in each region. The $\% \mathrm{sFe}_{\mathrm{REMIN}}$ was the same $\sim 45 \%$ at all stations investigated (Table 2), suggesting that remineralization or the exchange/scavenging reactions following remineralization partition $45 \%$ of remineralized $\mathrm{dFe}$ into the soluble phase and $55 \%$ into the colloidal phase throughout the North Atlantic.

However, the non-margin Line W stations (USGT11-03 through USGT11-08) still showed an absolute excess of $\mathrm{cFe}$ in the Central Waters of Figure $2 \mathrm{~d}$ (orange) that must have been contributed from an excess pre-formed cFe component.. To determine the \%cFe of the pre-formed Fe, the ratio of preformed $\mathrm{sFe}$ to pre-formed dFe was calculated by dividing the y-intercepts of the sFe-AOU and dFe-AOU plots; these ratios are tabulated as $\% \mathrm{sFe}_{\mathrm{PF}}$ in Table 2 . As expected, the Line $\mathrm{W}$ stations had a significantly lower $\% \mathrm{sFe}_{\mathrm{PF}}(27 \pm 13 \%)$ than that of the gyre stations $(57 \pm 15 \%)$, indicating that there was a higher contribution of pre-formed cFe to the Line $\mathrm{W}$ stations at intermediate depths than at the other stations. Also, the $\% \mathrm{sFe}_{\mathrm{PF}}$ and the $\% \mathrm{sFe}_{\mathrm{REMIN}}$ for the gyre and USGT10 stations were identical within error, which suggests that the pre-formed $\mathrm{dFe}$ of these stations may readily exchange with the remineralized dFe pools to produce an equally partitioned total $\mathrm{dFe}$ fraction. In contrast, along Line $\mathrm{W}$ the $\% \mathrm{sFe}_{\mathrm{PF}}(27 \%)$ was lower than the $\% \mathrm{sFe}_{\mathrm{REMIN}}(44 \%)$, suggesting that the pre-formed cFe excess may not exchange as rapidly with the remineralized dFe pool. A further discussion of the implications of this on the composition of the Line $\mathrm{W}$ excess $\mathrm{cFe}$ can be found in section 3.1.3.3. 
In deep waters, the $\mathrm{dFe}$ size partitioning along different water masses was assessed and compared to the $\mathrm{dFe}$ size in the same water masses in previously published studies. Below $1000 \mathrm{~m}, \mathrm{sFe}$ concentrations in North Atlantic Deep Water (NADW) were consistently between $0.25-0.35 \mathrm{nmol} / \mathrm{kg}$ (Figure 6), agreeing well with the nearly-constant, $\sim 0.30 \mathrm{nmol} / \mathrm{kg} \mathrm{sFe}$ concentrations previously reported for NADW in the North Atlantic (Fitzsimmons and Boyle, 2014b; Wu et al., 2001), through the South Atlantic (Bergquist et al., 2007), and into the Southern Ocean (Chever et al., 2010).

At USGT11-12 (Figure 6b), however, the water below $5000 \mathrm{~m}$ depth was determined to have 40\% OMPA-defined AABW influence (Jenkins et al., this issue), which was also evident from a drop in potential temperature to below $1.8^{\circ} \mathrm{C}$ (McCartney, 1992) and elevated concentrations of dissolved silica $(53 \mu \mathrm{mol} / \mathrm{kg})$. Waters shallower than $5000 \mathrm{~m}$ depth were instead composed of NADW components, namely Denmark Strait Overflow Water, Central Labrador Sea Water, and Iceland-Scotland Overflow Water. dFe concentrations dropped from $\sim 0.52 \mathrm{nmol} / \mathrm{kg}$ in NADW above 5000 to $\sim 0.43 \mathrm{nmol} / \mathrm{kg}$ below $5000 \mathrm{~m}$, with the $\% \mathrm{cFe}$ remaining roughly constant $52 \%$ in NADW, $46 \%$ at AAW depths. sFe concentrations below $5000 \mathrm{~m}$ were $0.20-0.25 \mathrm{nmol} / \mathrm{kg}$, significantly lower than the $0.33 \mathrm{nmol} / \mathrm{kg} \mathrm{sFe}$ found upstream in $\mathrm{AABW}$-influenced waters near $25^{\circ} \mathrm{S}$ (Bergquist et al., 2007), which are thought to have much less diluted AABW evidenced by their higher dissolved silicate concentration $(118 \mu \mathrm{mol} / \mathrm{kg})$ than the USGT11-12 AABW samples $\left(53 \mu \mathrm{mol} / \mathrm{kg}\right.$ ). This drop of $0.1 \mathrm{nmol} / \mathrm{kg}$ sFe from $25^{\circ} \mathrm{S}$ to $30^{\circ} \mathrm{N}$ cannot be attributed solely to increasing dilution with NADW because NADW has a higher sFe $(0.25$ $0.35 \mathrm{nmol} / \mathrm{kg})$ than the most dilute $30^{\circ} \mathrm{N}$ data deeper than $5000 \mathrm{~m}(0.23 \mathrm{nmol} / \mathrm{kg})$. This sFe decrease can likely be attributed to sorption/aggregation of $\mathrm{sFe}$ into cFe. In support of this we note that the cFe increased by the same $\sim 0.10 \mathrm{nmol} / \mathrm{kg}$ that $\mathrm{sFe}$ decreased along the $\mathrm{AABW}$ flow path, from $0.10 \mathrm{nmol} / \mathrm{kg}$ at $25^{\circ} \mathrm{S}$ to $\sim 0.20 \mathrm{nmol} / \mathrm{kg}$ at USGT11-12.

In summary, in abyssal waters we find rather constant sFe concentrations along NADW flow paths and increasing cFe concentrations along AABW flow paths. These patterns imply that transformations between soluble, colloidal, and particulate Fe pools are dynamic in the deep ocean and involve active exchange between soluble and colloidal pools via aggregation/disaggregation and/or sorption/desorption. As a result of this active exchange, scavenging residence times of individual Fe size fractions could not be calculated along the advective routes of these abyssal water masses, as these calculations require a quantitative accounting of these exchanges (such as the potential production of $\mathrm{cFe}$ from $\mathrm{pFe}$ and/or the reversible conversion between $\mathrm{sFe}$ and $\mathrm{cFe}$ ), which cannot be gleaned from the existing data. 


\subsubsection{Eastern margin: Mauritanian oxygen minimum zone (OMZ)}

Nearest Africa, a dFe maximum within the oxygen minimum zone (OMZ) reached concentrations of $1.85 \mathrm{nmol} / \mathrm{kg}$ (Figure 7a; USGT10-09 OMZ oxygen profile shown in Figure 6d). This dFe maximum extended westward past the TENATSO time-series station (station USGT10-12, reoccupied as USGT1124, Figure 7) to station USGT11-22 (Figure 2a) where maximum dFe concentrations were $\sim 1.0 \mathrm{nmol} / \mathrm{kg}$. The dFe peak extended from the DCM to $\sim 1500 \mathrm{~m}$ depth but was most intense between $350-500 \mathrm{~m}$ depth, coincident with the OMZ where oxygen concentrations were as low as $40 \mu \mathrm{mol} / \mathrm{kg}$ near Mauritania (Figure 6d; Hatta et al., this issue; Wu et al., this issue). dFe enrichments in the tropical North Atlantic OMZ have been reported previously (Bergquist and Boyle, 2006; Fitzsimmons et al., 2013; Measures et al., 2008; Rijkenberg et al., 2012). Linear dFe:AOU correlations in these tropical North Atlantic studies have been used to show that this $\mathrm{dFe}$ maximum, extending from $\sim 50^{\circ} \mathrm{W}$ to the Cape Verde Islands, is caused by remineralization of high Fe:C organic material (Fitzsimmons et al., 2013; Wu et al., this issue). Hatta et al.(this issue) show in their discussion of dFe-AOU regressions that while remineralization is surely the cause for the enhanced dFe in USGT11-22 through -24 and USGT10-11 and -12, there is an excess $\mathrm{dFe}$ at stations USGT10-09 and -10 that is likely derived from reducing African margin sediments. This distinction of a reducing margin source to USGT10-09 and USGT10-10 is corroborated by small increases in $\mathrm{Fe}(\mathrm{II})$ (Sedwick et al., this issue), dissolved manganese (Hatta et al., this issue), and isotopically light Fe (Conway and John, 2014), all of which are indicative of the influence of reduced porewaters.

Thus, an examination of the $\mathrm{dFe}$ size partitioning along the Mauritanian transect (stations USGT10-09 through USGT10-12) allowed a possible distinction of the size partitioning of sedimentderived $\mathrm{dFe}$ from that of remineralized $\mathrm{dFe}$. The observed $\mathrm{dFe}$ size fractionation for these stations (Figure 7) demonstrated that both soluble and colloidal Fe had maxima coincident with the dFe maximum. In

Figure $7 \mathrm{~d}$, it can be seen that the \%cFe through the region was $\sim 55-70 \%$, which is higher than the $40-60 \%$ cFe at stations USGT11-22 and USGT11-24 (Figure 2d). This apparent cFe increase arose at least in part because of the change in $\mathrm{sFe}: \mathrm{cFe}$ filtration on the two cruises: the $0.02 \mu \mathrm{m}$ Anodisc membranes used on USGT11 have a larger pore size than the 10kDa CFF filter used on USGT10 (Fitzsimmons and Boyle, 2014a). Notably, however, in the margin stations USGT10-09 and USGT10-10 (Hatta et al., this issue), peak sFe concentrations of $\sim 0.6 \mathrm{nmol} / \mathrm{kg}$ and peak cFe of $\sim 1.25 \mathrm{nmol} / \mathrm{kg}$ resulted in the same $\sim 55-70 \%$ partitioning into the colloidal fraction as at the stations less influenced by the margins, USGT10-11 and USGT11-12. Thus, remineralization and reducing sediments appear to partition dFe identically, or exchange between $\mathrm{dFe}$ size fractions in this region is rapid enough to produce a constant $\mathrm{dFe}$ size partitioning, regardless of $\mathrm{dFe}$ source. 
No enhanced $\mathrm{cFe}$ signature associated with $\mathrm{dFe}$ fluxes from reducing sediments was observed, and also no enhanced cFe signature associated with the Fe- and Mn-rich nepheloid layer near 3000m at USGT10-09 (defined in Ohnemus and Lam, this issue) was observed either. In fact, as can be seen in Figure $6 \mathrm{~d}$, the dFe concentration at USGT10-09 dropped below $1.0 \mathrm{nmol} / \mathrm{kg}$ in the two deepest samples at $\sim 3000 \mathrm{~m}$, indicating that the nepheloid layer may have promoted some dFe sorption/aggregation. The $\mathrm{sFe}$ concentrations decreased by a smaller magnitude than $\mathrm{dFe}$, such that the \%cFe decreased from $>60 \%$ throughout most deep water column to $\sim 50 \%$ near $3000 \mathrm{~m}$, implying a greater role for the sorption/aggregation of $\mathrm{cFe}$ in this nepheloid layer.

In their tropical North Atlantic study, Fitzsimmons and Boyle (2014b) found that along the edges of the $\mathrm{OMZ}$ where oxygen concentrations are $100-110 \mu \mathrm{mol} / \mathrm{kg}$, a unique $\mathrm{dFe}$ partitioning favors the formation of excess colloids. They corroborated this theory with data from Bergquist et al. (2007) showing an identical partitioning pattern favoring $\mathrm{cFe}$ on the western edge of the same tropical North Atlantic OMZ. On GA03 only one station satisfying this intermediate oxygen concentration was sampled: USGT11-22 (oxygen section in Figure S1d). At this station, the sFe was $0.375 \pm 0.014 \mathrm{nmol} / \mathrm{kg}(\mathrm{n}=3$ ), identical to the $\sim 0.4 \mathrm{nmol} / \mathrm{kg}$ reported by Fitzsimmons and Boyle, and cFe composed $55-60 \%$ of $\mathrm{dFe}$, identical to the $58 \pm 2 \% \mathrm{cFe}$ determined in Fitzsimmons and Boyle. Thus, our GA03 data from the more northern edge of the OMZ capture the same excess of colloidal Fe as Fitzsimmons and Boyle (2014b), despite being 1400-2000 km away from their western OMZ stations. While only an assessment of the Fe content in sediments along the edge of the OMZ could confirm this, the excess cFe along the edges of the OMZ could serve as an output pathway for the enhanced dFe from the OMZ. This has been shown in sediments surrounding the Peruvian $\mathrm{OMZ}$ where Fe redox chemistry plays a role in driving precipitation and loss of OMZ Fe(II) (Scholz et al., 2012). A non-redox mechanism involving aggregation through the cFe phase would be implied instead in the North Atlantic where oxygen concentrations are not as low.

In addition, the occupation of the TENATSO time series station on both cruise legs (stations USGT10-12 and USGT11-24) afforded us an opportunity to compare the two sFe:cFe ultrafiltration methods used in this manuscript over a full-depth profile (Figure 8). Oxygen and dFe concentrations were relatively constant over the two sampling years (Figure 8a), so natural variability in $\mathrm{dFe}$ was not a significant issue during this comparison (see more on dFe comparison at the TENATSO time-series station in Hatta et al., this issue). At the 24 depths sampled at TENATSO, sFe from the $10 \mathrm{kDa}$ CFF system used on USGT10 was on average $75 \pm 21 \%$ of the sFe from the $0.02 \mu \mathrm{m}$ Anopore filters used on

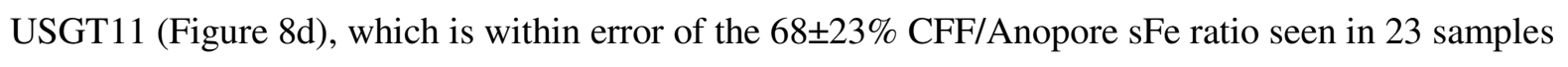
collected from the North Atlantic and Pacific Oceans (Fitzsimmons and Boyle, 2014b). The majority of this difference is attributed to a larger effective pore size in the $0.02 \mu \mathrm{m}$ Anopore filters (USGT11) than in the $10 \mathrm{kDa}$ CFF filters (USGT10). 
However, there is also spatial variability in the size distribution and/or composition of the 10 $\mathrm{kDa}-0.02 \mu \mathrm{m}$ Fe colloids that comprise the difference between the pore sizes of the two ultrafilters. This spatial variability explains the large (21\%) standard deviation in the sFe CFF/Anopore ratio measured at TENATSO and provides an oceanographic application of this filter comparison effort. As shown in Figure 8d, from the DCM through the upper portion of the OMZ ( 500m depth) the CFF/Anopore sFe ratio was $\leq 60 \%$, indicating where there was the largest component of $10 \mathrm{kDa}-0.02 \mu \mathrm{m}$ material (the smallest possible $\mathrm{cFe}$ measured here). Three processes could result in an enhanced abundance of these small colloids: (1) an external input of the small colloids, (2) increased in situ aggregation/disaggregation into the small colloid fraction, or (3) a unique ligand partitioning that forced $\mathrm{dFe}$ to favor the smallest colloid sizes. The low dFe concentrations at the DCM make the likelihood of an analytical bias quite high, so we will not consider the DCM partitioning comparison further. By $\sim 230 \mathrm{~m}$, however, $\mathrm{dFe}$ concentrations had begun to increase (Figure 2, 4, and S3; Hatta et al., this issue) and also the suspended particulate $\mathrm{Ba}, \mathrm{Fe}$, and $\mathrm{Al}$ had reached their maxima (Ohnemus and Lam, this issue), indicating that by $230 \mathrm{~m}$ the disaggregation of large particles had begun to outcompete aggregation. Thus, the enrichment of small-colloidal Fe at $230 \mathrm{~m}$ is likely a result of particle disaggregation all the way to the smallest 10kDa$0.02 \mu \mathrm{m}$ sizes. In contrast, these small colloids in the $10 \mathrm{kDa}-0.02 \mu \mathrm{m}$ size fraction were negligible in the abyssal ocean (2500-3500 m), despite the abundance of larger colloids $(0.02-0.2 \mu \mathrm{m})$ at elevated concentrations of $0.35-0.55 \mathrm{nmol} / \mathrm{kg}$ (Figure $8 \mathrm{c}$ ). These patterns indicate that the size distribution of marine $\mathrm{dFe}$ is variable both with space and with depth and warrants future exploration.

\subsubsection{Western boundary (Line W)}

A dFe maximum of $0.8-1.2 \mathrm{nmol} / \mathrm{kg}$ is apparent at intermediate depths of the western region of GA03 (USGT11-02 through USGT11-10), which we refer to as the Line W transect due to its overlap with the Line $\mathrm{W}$ time-series transect between Woods Hole and Bermuda (Joyce et al., 2005). The Line W $\mathrm{dFe}$ enrichment extended offshore from the margin along Line $\mathrm{W}$ at 500-2500 $\mathrm{m}$ depth, reaching eastward even beyond the BATS station along a narrower depth window of 900-2000 m (Figure 2a). As described in Hatta et al. (this issue), this dFe feature is coincident with elevated CFC concentrations that identify the presence of Labrador Sea Water (LSW). LSW can also be identified by the relatively lower silicate concentrations flowing along these aforementioned depths (Figure S2c). LSW has been found to circulate along the deep western boundary current of North America along the continental slope (Talley and McCartney, 1982) but also into the subtropics via an additional interior pathway that splits off to the east of the Grand Banks (Bower et al., 2011; Bower et al., 2009). Hatta et al. (this issue) hypothesize that LSW dFe was acquired from deep western boundary sediments during transport from the Labrador Sea. They support this hypothesis by noting coincident dissolved Mn and $\mathrm{Al}$ (Measures et al., this issue) 
maxima in LSW, both of which are hypothesized to be margin derived, as well as an excess of ${ }^{228} \mathrm{Ra}$ (Charette et al., this issue), which indicates that LSW along Line W has been in contact with sediments during the last $\sim 30$ years.

The Line W dFe enrichment in LSW is partitioned 60-80\% into the colloidal size fraction (Figure 2d), a much higher $\mathrm{cFe}$ contribution than in intermediate waters from the rest of GA03, where an 50:50\% sFe:cFe partitioning is hypothesized to result from remineralization (Section 3.1.3.1). As a first approximation, the maximum possible cFe concentration derived from external sources to LSW can be calculated by assuming a 45:55\% sFe:cFe remineralization ratio (Table 2) and that all of the sFe measured in LSW derived from remineralization: the resulting LSW cFe excess is $0.10-0.38 \mathrm{nmol} / \mathrm{kg}$. This Line W $\mathrm{cFe}$ enrichment must be either pre-formed $\mathrm{cFe}$ from the Labrador Sea surface ocean or cFe acquired from margin sediments during LSW transit. The $\mathrm{SF}_{6}$ age of LSW along Line $\mathrm{W}$ is approximately 25 years since contact with the surface ocean (William Smethie, personal communication), which is shorter than estimates of cFe scavenging times in NADW of 140 \pm 100 years (Bergquist et al., 2007). This suggests that it would be possible for pre-formed Labrador Sea cFe to escape scavenging during transit to the subtropics, so long as the scavenging residence times in LSW and tropical NADW are the same. There is no published surface dFe data from the Labrador Sea, and thus we cannot confirm or reject a pre-formed cFe source. However, we do note that dust models do not predict large dust inputs to the Labrador Sea (Jickells et al., 2005; Mahowald et al., 2005), and surface dissolved Al concentrations in the Labrador Sea are very low (Hall and Measures, 1998), minimizing the potential for an atmospheric pre-formed $\mathrm{dFe}$ source. While surface Labrador Sea waters could have acquired cFe enrichments from sea ice or glacial meltwaters (Bhatia et al., 2013; Lannuzel et al., 2007), a more likely mechanism of Line W pre-formed cFe enrichment in LSW is cFe resuspension during passage along the continental slope, following Hatta et al.'s discussion of the continentally-derived $\mathrm{Mn}, \mathrm{Al}$, and ${ }^{228} \mathrm{Ra}$ in LSW.

Regardless of which individual process added the cFe to LSW, all possible sources are lithogenic. We also know that this cFe was maintained in excess of sFe throughout the LSW water mass, while in the other intermediate/deep waters of GA03 where the only source was remineralization the $\mathrm{sFe}$ and $\mathrm{cFe}$ concentrations were more equal. To explain this difference, we suggest that some or all of the excess cFe in LSW may be inorganic in composition (such as colloidal Fe oxyhydroxides or silicates) as opposed to being bound by organic ligands, which would be the working assumption since $>99.9 \%$ of $\mathrm{dFe}$ is thought to be organically bound in the open ocean (Rue and Bruland, 1995). An inorganic composition of the LSW cFe component would make sense if the cFe was directly swept up from sediments during the flow of LSW along the continental margin and slope. In fact, previous studies have shown that a portion of the cFe phase is inorganic in coastal and nearshore environments (Wells and Goldberg, 1992, 1994). Furthermore, an inorganic cFe component to LSW, which would presumably be quite refractory, would 
explain why pre-formed cFe in LSW does not exchange with the sFe phases and re-equilibrate to a 50$50 \%$ partitioning, as observed in the rest of GA03 (Table 2, discussed above). Moreover, the Fe isotope ratio of $\mathrm{dFe}$ in LSW close to the western margin (USGT11-01 through USGT11-03) ranged from 0.0 to $+0.2 \%$, which is noticeably lower than the $\mathrm{dFe} \delta^{56} \mathrm{Fe}$ at similar depths of surrounding stations (Conway and John, 2014). These LSW $\delta^{56} \mathrm{Fe}$ values are similar to the $+0.1 \%$ ocrustal signature (Beard et al., 2003), which would be expected if the LSW excess cFe included a significant contribution of inorganic Fe with a crustal composition. While these data are not sufficient to determine definitely whether $\mathrm{cFe}$ in the western basin is inorganic (since organically-bound dFe fractionated uniquely from that at similar depths nearby could also result in this isotope composition), the potential presence of inorganic $\mathrm{cFe}$ is biogeochemically relevant because it may be significantly less bioavailable than the organically-bound cFe in the N. Atlantic (Rich and Morel, 1990).

Above and below the intermediate LSW depth range, however, the entire Line W water column had an enhanced \%cFe of 60-70\% (Figure $2 \mathrm{~d}$ and Figure 6a). The upper 500m of Line W was composed of Shelf/Slope Waters (USGT11-01 and USGT11-02), which flow southward along the continental margin, and Gulf Stream Waters (USGT11-03), which flow northward farther offshore (see the ADCP data from these stations for water mass assignment in Hatta et al., this issue; the physical oceanography of the upper ocean of Line W is summarized in Joyce et al., 2005). Only the Shelf/Slope Water-impacted USGT11-02 showed dFe concentrations greater than $0.4 \mathrm{nmol} / \mathrm{kg}$, which Hatta et al. (this issue) attribute to direct $\mathrm{dFe}$ inputs from the North American shelf. In both water masses, upper ocean waters contained a $\geq 60 \%$ cFe composition, and we propose that, similar to LSW, this colloidal Fe could contain inorganic $\mathrm{cFe}$ acquired from the continental shelf.

Finally, we note that the Line W nepheloid layers of stations USGT11-06 through USGT11-10 may have contributed the cFe excesses along the deep western boundary (Figure 2d). It has been known for some time that in this region particulate material can be resuspended into the water column hundreds of meters above the seafloor (Brewer et al., 1976). On GA03 an example of these increased particle loadings is recorded at USGT11-06 by the reduction in the transmissometer signal (Figure 6a). Ohnemus and Lam (this issue) further defined the depths of each of these nepheloid layers using their measured particulate loadings, even recording a >1000 m resuspension above the bottom at USGT11-10. In the Line W nepheloid layers, the $\mathrm{dFe}$ was $\sim 55-65 \%$ colloidal, and thus these nepheloid layers may serve as the source of excess colloids to the water column. Similarly, very near the Line W stations, Wells and Goldberg (1994) found evidence for increased colloid volume in nepheloid layers off the Scotian shelf, which they hypothesized was a result of episodic high-flow "storm" events that pushed sediments containing colloidal material into the deep water column (Gross et al., 1988). 


\subsubsection{TAG hydrothermal system}

Station USGT11-16 targeted the TAG (Trans-Atlantic Geotraverse) hydrothermal field centered at $26^{\circ} 8.2^{\prime} \mathrm{N}$ along the Mid-Atlantic Ridge in order to sample the proximal influences of the known black smoker hydrothermal venting of high-Fe fluids on the geochemistry of the deep North Atlantic water column (Figure 9). The TAG hydrothermal field is located on the eastern wall of the slow-spreading $(<2$ $\mathrm{cm} / \mathrm{y}$ ) Mid-Atlantic Ridge rift valley in 3650m water depth (Rona et al., 1986). TAG black smoker vents have been found to release fluids with extremely high $\mathrm{dFe}$ concentrations of $\sim 5.0-5.5 \mathrm{mM}$ (Chiba et al., 2001), nearly six orders of magnitude higher concentration than typical North Atlantic abyssal dFe concentrations. A decrease in light transmission >3000 m at USGT11-16 (Figure 9c) indicates that we encountered the particle-rich neutrally buoyant plume. In the portion of the seawater mixed, non-buoyant plume that we sampled proximal to the TAG site, an elevated dFe concentration of $66.4 \mathrm{nmol} / \mathrm{kg}$ was detected, $89-96 \%$ of which was partitioned into the colloidal size fraction (Figure 9c), with sFe concentrations in the five highest-dFe samples reaching only $2.0-7.4 \mathrm{nmol} / \mathrm{kg}$. While colloidal Fe oxyhydroxides have previously been hypothesized to account for the high concentrations of dFe at TAG (James and Elderfield, 1996), the discovery that 58-100\% of this dFe is composed of Fe(II), not Fe(III) (Sedwick et al., this issue), instead point toward a TAG non-buoyant plume dFe composition of colloidal Fe sulfide nanoparticles (Yucel et al., 2011) and/or organically-bound colloidal Fe(II) species (Toner et al., 2009).

The two stations flanking the TAG station afforded us the opportunity to determine whether hydrothermal-derived dFe is transported away from the MAR vent system in the dissolved phase, and if so which size fraction of dFe persists. Stations USGT11-14 and USGT11-18 were each $\geq 500 \mathrm{~km}$ away from the MAR (to the west and east, respectively, Figure 1). The recently proposed "leaky vent" hypothesis posits that instead of quantitatively precipitating at the vent site, some hydrothermal $\mathrm{Fe}$ is transferred long distances in the dissolved phase and contributes significantly to the deep ocean $\mathrm{dFe}$ inventory (Bennett et al., 2008; Boyle and Jenkins, 2008; Fitzsimmons et al., 2014; Toner et al., 2012). This distal contribution of hydrothermal Fe to deep ocean dFe has been modeled (Saito et al., 2013; Tagliabue et al., 2010), and in the Pacific distal hydrothermal dFe transport thousands of kilometers from the vent site has been demonstrated (Fitzsimmons et al., 2014; Nishioka et al., 2013), confirming the "leaky vent" hypothesis. Determining whether this also occurs at higher abyssal oxygen concentrations in the North Atlantic (Field and Sherrell, 2000), and if so how the dFe size partitioning plays a role in this $\mathrm{dFe}$ persistence, was a major goal of this investigation.

While no hydrothermal dFe excess was recorded at USGT11-18 to the east of the MAR (Hatta et al., this issue), a hydrothermal signal of $\sim 1 \mathrm{nmol} / \mathrm{kg} \mathrm{dFe}$ at USGT11-14 to the west of the MAR was recorded at a depth of $2500 \mathrm{~m}$, shallower than the TAG site (Figure 9a). The only possible source of this 
enhanced dFe at USGT11-14 is the Mid-Atlantic Ridge, which demonstrates distal transport of dFe at least $500 \mathrm{~km}$ in the North Atlantic, confirming the "leaky vent" hypothesis in the North Atlantic (Bennett et al., 2008; Boyle and Jenkins, 2008; Fitzsimmons et al., 2014; Toner et al., 2012). If background NADW dFe concentrations of $\sim 0.6 \mathrm{nmol} / \mathrm{kg}$ are subtracted from the maximum $\mathrm{dFe}$ concentrations at USGT11-14, a hydrothermally-derived excess of $\sim 0.4 \mathrm{nmol} / \mathrm{kg}$ remains between $2100-3000 \mathrm{~m}$ at this site. Of this $\sim 0.4 \mathrm{nmol} / \mathrm{kg}$ hydrothermal $\mathrm{dFe}$, soluble Fe contributed 9-18\% (subtracting background NADW sFe of $\sim 0.27 \mathrm{nmol} / \mathrm{kg}$; Figure $9 \mathrm{a}$ ). This is higher than the $4-11 \% \mathrm{sFe}$ found proximal to the TAG site at USGT11-16 (Figure 9c). Although this could be attributed to a different Fe chemistry in the hydrothermal vent sourcing the dFe enrichment at USGT11-14, which is potentially not TAG since there is no direct abyssal circulation route between USGT11-16 and USGT11-14, another explanation is that the percent of truly soluble $\mathrm{dFe}$ actually increases with increasing distance from vent fields. The same pattern has been observed in the eastern South Pacific for dFe released from East Pacific Rise hydrothermal vents (Fitzsimmons et al., 2014). If true, this would indicate that the soluble fraction more efficiently "leaks" from hydrothermal vents, providing a clue about the mechanism of hydrothermal $\mathrm{dFe}$ preservation during "leaky vent" hydrothermal dFe persistence.

\subsection{Synthesis model of dFe size partitioning in the North Atlantic}

The North Atlantic Ocean has been sampled more extensively for the size fractionation of $\mathrm{dFe}$ into soluble and colloidal phases than any other ocean basin (see global map of previous studies in Fitzsimmons and Boyle, 2014a). Nonetheless, a consensus on the factors controlling dFe size partitioning in this region has not yet emerged. We believe that the GA03 transect captures most of the major dFe inputs into the North Atlantic that might influence dFe partitioning and also provides the highest spatial and depth resolution sampled for size fractionated dFe in the Atlantic to date. Thus, this GEOTRACES dataset is optimally suited for resolving hypotheses of which processes control the size partitioning of marine $\mathrm{dFe}$ in the Atlantic Ocean.

First, we review the findings of previous North Atlantic dFe size partitioning studies (cruise locations indicated on the Figure 1 map). Originally, Bergquist et al. (2007) posited that variability in the $\mathrm{cFe}$ phase was responsible for the variability in North Atlantic $\mathrm{dFe}$, while sFe remained relatively constant with depth at $\sim 0.3 \mathrm{nmol} / \mathrm{kg}$. This partitioning pattern is apparent in a reproduction of their size fractionated dFe data in Figure 10a, where dFe was well correlated with cFe but did not correlate with invariant sFe. In contrast, over a larger swath of stations in the tropical North Atlantic, Fitzsimmons and Boyle (2014b) found that both $\mathrm{sFe}$ and cFe contributed to dFe variability at nearly constant 50:50\% distributions (Figure 10b). They concluded that either the size partitioning of organic Fe-binding ligands controls the overall partitioning of dFe in the North Atlantic or that North Atlantic dFe has a "steady 
state" dFe partitioning pattern where exchange rates between soluble and colloidal fractions are set and produce the constant observed dFe partitioning (potentially overlain by inert or fresh Fe inputs containing uniquely size-fractionated $\mathrm{Fe}$ in some places).

To discriminate between these alternatives, we focused on the correlations between different $\mathrm{dFe}$ size fractions from the GEOTRACES transect for the 2011 (c-d) and 2010 (e) cruises (Figure 10). Importantly, the regressed data only includes depths below the DCM, and hydrothermally-affected depths of USGT11-14 and USGT11-16 were also excluded. As the data in Figure 10c-e shows, since sFe and cFe both increase as $\mathrm{dFe}$ increases, both size fractions must contribute to $\mathrm{dFe}$ variability. Thus we conclude that Bergquist et al.'s hypothesis of direct cFe control on dFe variability does not apply broadly across the North Atlantic.

It is difficult to evaluate Fitzsimmons and Boyle's first hypothesis (2014b) that the size partitioning of organic Fe-binding ligands directly controls the size partitioning of dFe, since there is so little data available on the size partitioning of organic Fe-binding ligands in the ocean, especially in the intermediate and deep ocean. The existing published measurements from the upper ocean, however, have suggested that the size partitioning of organic Fe-binding ligands does not predict the size partitioning of dFe (Boye et al., 2010; Cullen et al., 2006; Thuróczy et al., 2010). Cullen et al. (2006) interpreted this result as being caused by a missing "inert" colloidal Fe-binding ligand fraction that is not detected electrochemically. Using size-fractionated Fe ligand data from the upper ocean of GA03, Fitzsimmons et $a l$. (in press) question whether inorganic $\mathrm{cFe}$ might be the cause of this divergence between the ligandpredicted and observed dFe size fractionation. However, since unique dFe sources and transformation processes related to biological activity and particle dynamics occur in the upper ocean that could drive deviations in $\mathrm{dFe}$ size partitioning from what is expected by the ligand size partitioning (see Sections 3.1.1-3.1.2), we must leave open the possibility that in the intermediate and deep ocean ligand size partitioning and associated ligand exchange does control dFe size partitioning.

Nonetheless we instead focus on the hypothesis of Fitzsimmons and Boyle (2014b) that there is a "steady state" dFe re-partitioning into soluble and colloidal phases that is constant for a given region, and we develop a dFe partitioning model for all depths below the DCM based on this hypothesis. An exchange model must be implicated because new dFe inputs such as dust, margin sediments, and hydrothermal venting all result in cFe-enriched inputs (see sections 3.1.1 and 3.1.3.3-4) that cannot by themselves explain the $\sim 50: 50 \% \mathrm{sFe}: \mathrm{cFe}$ partitioning observed in the subsurface North Atlantic Ocean. Thus, we consider other potential pathways for $\mathrm{dFe}$ inputs/transformations in the deep ocean: remineralization, scavenging, and Fe exchange. First, we considered whether remineralization could alone create the $\sim 50: 50 \% \mathrm{sFe}: \mathrm{cFe}$ partitioning via equal input directly into $\mathrm{sFe}$ and $\mathrm{cFe}$ pools. While we have no evidence against this, any subsequent scavenging or exchange of Fe between size fractions would change 
the observed dFe size partitioning, and also uniquely partitioned pre-formed dFe pools would impart an unequal partitioning to deep waters that is not supported by the equally-partitioned results in Figure 10be. Instead, we suggest that the constant partitioning is driven by a "steady state" of the sum of dFe exchange processes directly following remineralization (including ligand exchange, sorption/desorption, and aggregation/disaggregation, indicated with solid black arrows in Figure 11a); in other words, the rates of these $\mathrm{dFe}$ exchange processes are equal and result in the constant partitioning observed in the subsurface North Atlantic Ocean. Thus, rather than dFe in a given seawater parcel having a fixed concentration of $\mathrm{sFe}$ and a variable concentration of $\mathrm{cFe}$ that determines the magnitude of $\mathrm{dFe}$ (Bergquist et al., 2007), the $\mathrm{dFe}$ in a given water parcel will have a fixed percentage of $\mathrm{sFe}$ and $\mathrm{cFe}$ set by the relative rates of exchange between $\mathrm{sFe}$ and $\mathrm{cFe}$ fractions (Figure 11a).

This "steady state" model of $\mathrm{dFe}$ partitioning is supported by the Fe:C errors from the three regions of GA03 in Table 2 . The fact that the $\% \mathrm{sFe}_{\mathrm{REMIN}}$ across the three regions are identical within error indicates that a single process is informing the $\mathrm{dFe}$ size partitioning in all three regions, which we propose is remineralization and/or the immediate exchange reactions following remineralization. Furthermore, the similarity between the $\% \mathrm{sFe}_{\mathrm{REMIN}}$ and the $\% \mathrm{sFe}_{\mathrm{PF}}$ for most of GA03 likely indicates that the pre-formed and remineralized $\mathrm{dFe}$ pools are exchanging with each other, forming the total steady state 50:50\% sFe:cFe partitioning observed in the subsurface of Figure $2 \mathrm{~d}$.

The only region where the overall partitioning was not 50:50\% sFe:cFe was along Line $\mathrm{W}$, where in Section 3.1.3.3 we argue that a portion of the cFe is inorganic Fe. This highlights the single caveat to the steady state partitioning model: in order to reach the observed 50:50\% sFe:cFe partitioning, all measurable $\mathrm{dFe}$ must be labile to exchange with sFe and cFe pools. If the Line $\mathrm{W}$ pre-formed $\mathrm{cFe}$ is composed of inorganic $\mathrm{Fe}$, it may not be exchangeable with the otherwise organically-bound $\mathrm{sFe}$ and $\mathrm{cFe}$ pools of the deep ocean on the timescales of the transit between the margin source and our sampling locations. Thus, the Line $\mathrm{W}$ pre-formed $\mathrm{dFe}$ remains mostly colloidal, and Line $\mathrm{W}$ appears to have a cFe excess (Figure 2d).

Thus, the "steady state" dFe size partitioning model fails under two conditions: 1) not enough time has passed for the exchange reactions to reach steady state, or 2) some of the dFe is not kinetically labile to exchange on relevant timescales. A prime example of this situation is the upper ocean of the North Atlantic (Figure 11b), where one or both of these conditions prevents dFe from reaching the constant 50:50\% sFe:cFe partitioning observed in the subsurface ocean. As discussed in sections 3.1.1 and 3.1.2 (and observed in Figure 10c-e, open circles), surface dFe was mostly colloidal (Figure 2), while DCM dFe was mostly soluble (Figure 4), with a nearly constant sFe concentration above the DCM. The surface cFe excess likely arises from recent dust inputs that have not had sufficient time to exchange with the ambient $\mathrm{dFe}$ pools or that are potentially inorganic in composition and cannot exchange with the 
ambient surface $\mathrm{dFe}$ (Section 3.1.1). Additionally, biological organisms take up dFe rapidly at these depths, potentially favoring one $\mathrm{dFe}$ size fraction over another, and $\mathrm{sFe}: \mathrm{cFe}$ exchange kinetics may not be able to keep up. At the DCM, cFe may be favored after rapid scavenging/aggregation kinetics that outcompete the regular sFe:cFe exchange kinetics. Thus, steady state dFe partitioning is not reached, and euphotic zone $\mathrm{sFe}$ and $\mathrm{cFe}$ appear to cycle independently.

Some subsurface regions along GA03 also failed to reach dFe size partitioning steady state. At and downstream of the MAR, hydrothermal inputs of inorganic dFe may not readily exchange with deep ocean $\mathrm{sFe}$ and $\mathrm{cFe}$ pools on relevant exchange timescales. Alternatively, the aggregation and scavenging reactions in these fluids with modified chemistry and particulate loadings may have had faster kinetics (or were simply more abundant) than the sFe:cFe exchange reactions in the deep ocean. We also note that the subsurface dFe profiles of Bergquist et al. (2007, Figure 10a) may also not have re-partitioned to steady state for reasons of $\mathrm{dFe}$ composition and/or kinetics. At their $30^{\circ} \mathrm{N}$ site, a LSW influence at mid-depths likely resulted in their observed a cFe excess, just as in the Line W stations of GA03 (Section 3.1.3.3), and at their $10^{\circ} \mathrm{N}$ site, oxygen concentrations were at the intermediate concentration that Fitzsimmons and Boyle (2014b) showed favors the formation of $\mathrm{cFe}$, presumably via non-steady state exchange of $\mathrm{dFe}$ during mixing of low-Fe gyre water with high-Fe OMZ water (Section 3.1.3.2).

Thus, our model of steady-state exchange between the sFe and cFe pools explains the nearconstant 50:50\% sFe:cFe partitioning of the subsurface North Atlantic Ocean (Figure 11). This is most clearly visualized in the $\mathrm{sFe}: \mathrm{cFe}$ regressions on the right panel of Figure 10 (c-e), where it is shown that subsurface $\mathrm{sFe}$ and cFe cycle synchronously in the North Atlantic: where sFe was low, cFe was also low, and vice-versa. The relation of the $\mathrm{sFe}: \mathrm{cFe}$ trend to the 1:1 line also gives an indication of the general partitioning of the $\mathrm{dFe}$ in water from a given region: in North Atlantic gyre waters, half of the $\mathrm{dFe}$ was $\mathrm{cFe}$ and half was $\mathrm{sFe}$, while in Line $\mathrm{W}$ waters, more than half of the $\mathrm{dFe}$ was colloidal. We must emphasize that these "steady state" dFe partitioning patterns are dependent on the operational definitions of sFe utilized: using the $0.02 \mu \mathrm{m}$ sFe size cutoff, typical "steady state" dFe partitioning was $\sim 50 \% \mathrm{sFe}$ (Figure 2d), but using a smaller $10 \mathrm{kDa}$ sFe pore size in the 2010 cruise, "steady state" partitioning was only $\sim 35 \% \mathrm{sFe}$ (Figure $4 \mathrm{~d}$ ).

\subsection{Size fractionated $\mathrm{dFe}$ stable isotope ratios}

We also investigated the $\mathrm{Fe}$ isotopic signature $\left(\delta^{56} \mathrm{Fe}\right)$ of the $\mathrm{sFe}$ and $\mathrm{dFe}$ pools in order to test the "steady state" dFe partitioning model described above. Seawater dissolved Fe isotopes have previously been used both to trace different sources of Fe to the oceans and to study the transformations of dissolved Fe between species and phases (John and Adkins, 2012; John et al., 2012; Lacan et al., 2008; Radic et al., 2011). Measurements of seawater dissolved $\delta^{56} \mathrm{Fe}$ from GA03 have been used to constrain sources of $\mathrm{Fe}$ 
to the North Atlantic (Conway and John, 2014), while measurements of particulate $\delta^{56} \mathrm{Fe}$ have been used to investigate sources of particulate Fe to the North Atlantic and explore dissolved-particulate interactions (Revels et al., this issue) We focus here on what $\delta^{56} \mathrm{Fe}$ suggests about the sources and cycling of the individual $\mathrm{sFe}$ and $\mathrm{cFe}$ fractions.

The size partitioned Fe isotope ratio results are shown in Figure 12, and the data and errors are tabulated online in the Supplementary Materials. To separate sFe from cFe in these isotope samples, the $10 \mathrm{kDa}$ CFF system was chosen over Anopore filtration because of the large sample volumes required for isotopic analysis (Fitzsimmons and Boyle, 2014a). However, as discussed for the TENATSO time-series station (Figure 8; Section 3.1.3.2), the general dFe size partitioning pattern resulting from CFF was the same as that derived from Anopore filtration: surface $\mathrm{dFe}$ was dominated by $\mathrm{cFe}(85 \%$ and $56 \%$ using CFF at USGT11-11 and USGT11-21, respectively), while intermediate/deep ocean dFe partitioning neared 50:50\% sFe:cFe, ranging from $48-63 \% \mathrm{cFe}$.

Similar to the concentration partitioning patterns, the $\mathrm{dFe}$ isotope partitioning was different in the surface compared to subsurface waters ( $>300 \mathrm{~m}$, Figure 12). In the surface, the $\delta^{56} \mathrm{Fe}$ of sFe was quite heavy at both stations $(+1.33 \pm 0.11 \%$ and $+1.49 \pm 0.18 \%$ at USGT11-11 and USGT11-21, respectively, $\pm 2 \sigma \mathrm{SE})$ relative to the $\delta^{56} \mathrm{Fe}$ of bulk dFe $(+0.52 \pm 0.06 \%$ and $+0.45 \pm 0.07 \%$, respectively). If $\mathrm{cFe}$ is calculated as $\mathrm{dFe}$ minus $\mathrm{sFe}$ and the $\delta^{56} \mathrm{Fe}$ of $\mathrm{cFe}$ is calculated by isotope mass balance, then the $\delta^{56} \mathrm{Fe}$ of surface $\mathrm{cFe}$ was more variable $\left(+0.38 \pm 0.12 \%\right.$ and $-0.36 \pm 0.22 \%$, respectively). In contrast, the $\delta^{56} \mathrm{Fe}$ of subsurface $\mathrm{sFe}$ and bulk dFe were identical within error at all but one subsurface depths sampled (see Figure 12). We note that the bulk $\mathrm{dFe} \delta^{56} \mathrm{Fe}$ values reported here are in good agreement with those reported by Conway and John (2014) for similar depths of nearby stations. We also emphasize that these $\mathrm{sFe}$ and $\mathrm{dFe}$ isotope ratios are not likely to have been fractionated during filtration for three reasons. First, $\mathrm{sFe}$ appears to be wholly recovered using this CFF system and thus would not be fractionated as a result of poor recovery (Fitzsimmons and Boyle, 2014a). Second, sFe samples collected from the surface Pacific Ocean using the same CFF system did not result in positively fractionated $\mathrm{sFe} \delta^{56} \mathrm{Fe}$ (Fitzsimmons and Conway, unpublished results). Finally, stepwise ultrafiltration through $0.4 \mu \mathrm{m}, 0.22 \mu \mathrm{m}, 0.1 \mu \mathrm{m}, 100$ $\mathrm{kDa}, 10 \mathrm{kDa}$, and $1 \mathrm{kDa}$ membranes resulted in equivalent $<1 \mathrm{kDa} s F e$ isotope ratios as direct filtration from $0.4 \mu \mathrm{m}$ to $1 \mathrm{kDa}$ using similar ultrafiltration membranes in a river water study (Ilina et al., 2013), suggesting that ultrafiltration does not fractionate Fe isotopes in natural waters.

The size fractionated $\mathrm{dFe}$ isotope patterns are consistent with the dFe partitioning and exchange model presented in Figure 11. The fact that the $\mathrm{sFe}$ and $\mathrm{cFe} \delta^{56} \mathrm{Fe}$ are different in the surface but similar in the intermediate/deep ocean indicates either a change in the sources of Fe to the colloidal and soluble phases in the surface than in the deep ocean or the presence of different fractionation pathways at different depths. For example, the identical $\delta^{56} \mathrm{Fe}$ values for $\mathrm{sFe}$ and $\mathrm{dFe}$ (and thus $\mathrm{cFe}$ ) in the subsurface 
suggest that subsurface $\mathrm{sFe}$ and $\mathrm{cFe}$ have either the same source and undergo exchange reactions that are non-fractionating, have different sources with identical $\delta^{56} \mathrm{Fe}$ signatures, or have been isotopically equilibrated via $\mathrm{Fe}$ exchange. The isotopic similarity between $\mathrm{sFe}$ and $\mathrm{cFe}$ across the entire section in the deep ocean is particularly surprising given the wide variety of processes which could influencing subsurface $\delta^{56} \mathrm{Fe}$ including variable remineralization rates (as reflected in changing AOU values, Figure 5), different pre-formed $\mathrm{dFe}$ and $\delta^{56} \mathrm{Fe}$ ratios in different water masses (e.g. the Surface Waters, Central Waters, Atlantic Equatorial Waters, Mediterranean Outflow Waters, and Irminger Sea Waters; Jenkins et $a l$., this issue), and variable scavenging and exchange reactions that occur in the subsurface ocean as a function of variable particle loading/composition and ligand composition. A contribution of pre-formed $\mathrm{sFe}$ and $\mathrm{cFe}$ with different concentrations and/or isotope ratios could explain the different $\mathrm{Fe}$ isotope values between $\mathrm{sFe}(+0.37 \pm 0.16 \%$ o $)$ and $\mathrm{dFe}(+0.78 \pm 0.08 \%$ ) at $531 \mathrm{~m}$ at USGT11-11 if the pre-formed sFe in the Southwest Atlantic Central Waters partially feeding that depth was isotopically lighter than the $\mathrm{sFe}$ in the North Atlantic Central Water fully feeding the $286 \mathrm{~m}$ sample at the same station. However, the fact that the $\mathrm{sFe}$ and $\mathrm{cFe}$ isotope ratios are nearly identical in the other intermediate/deep ocean samples, yet different water masses feed those stations as well, suggests instead another deep ocean process is regulating $\mathrm{Fe}$ isotope ratios at depth.

There is no evidence in the literature that remineralization fractionates Fe isotopes (John and Adkins, 2012), especially between soluble and colloidal phases, nor that scavenging induces an Fe isotope effect (Radic et al., 2011). Thus, for the $\mathrm{sFe}$ and $\mathrm{cFe}$ to have both nearly identical Fe isotope signatures and equal concentrations in the intermediate/deep ocean, $\mathrm{sFe}$ and $\mathrm{cFe}$ would have to be equally influenced by non-fractionating remineralization and/or scavenging pathways as well as have identical isotope compositions in water masses delivering pre-formed Fe. More likely, the Fe exchange processes following remineralization (such as sorption/desorption or aggregation/disaggregation associated with scavenging) that we propose in the dFe size partitioning model of Figure 11 might produce, with sufficient reaction time, the constant 50:50\% sFe:cFe partitioning and isotope equilibrium observed between $\mathrm{sFe}$ and $\mathrm{cFe}$ in the North Atlantic. This is similar to the isotopic buffering between particles and organic ligands that John and Adkins (2012) hypothesized to cause the nearly constant dFe isotope ratios nearby in the North Atlantic.

In the surface ocean, however, the isotopically heavier $\mathrm{sFe}$ relative to $\mathrm{cFe}$ and bulk $\mathrm{dFe}$ suggest that $\mathrm{sFe}$ and $\mathrm{cFe}$ have unique sources conferring different $\mathrm{Fe}$ isotope signatures or that $\mathrm{sFe}$ and $\mathrm{cFe}$ are fractionated separately. Surface dFe at USGT11-11 and USGT11-23 are both thought to have an aerosol source (Section 3.1.1), so a further Fe transformation process must be implicated to explain the different $\mathrm{sFe}$ and $\mathrm{cFe} \delta^{56} \mathrm{Fe}$ values. If North Atlantic surface $\mathrm{cFe}$ was composed of inorganic pieces of dust, it would likely have a crustal $\delta^{56} \mathrm{Fe}$ value near $+0.1 \%$ (Beard et al., 2003). Neither station had a surface 
calculated $\mathrm{cFe} \delta^{56} \mathrm{Fe}$ of $+0.1 \%$, but both stations' colloidal $\delta^{56} \mathrm{Fe}$ were close to $+0.1 \%$ when propagated errors are considered, so this hypothesis cannot be rejected without future testing.

Nonetheless, $\mathrm{Fe}$ isotope fractionation must have occurred during dust solubilization and/or binding by organic ligands, since the dust-derived bulk $\mathrm{dFe} \delta^{56} \mathrm{Fe}$ of the surface ocean is isotopically heavier than the $+0.1 \%$ o measured in dust itself (Figure 12). Isotopically heavy aerosol-derived surface $\mathrm{dFe}$ is somewhat surprising, given that the only published results of the Fe isotope ratios derived from aerosol solubilization in aerosol leach solutions suggested no significant fractionation ( $\mathrm{pH} 4.7$ ammonium acetate leach, Waeles et al., 2007). However, the isotope fractionation may be controlled over longer timescales (an equilibrium isotope effect), such as during the non-reductive dissolution of Fe from sediment particles (Homoky et al., 2013; Radic et al., 2011) or during the binding of Fe by organic ligands (Dideriksen et al., 2008). One laboratory study has suggested that stronger ligands bind heavier Fe than weaker ligands, in accordance with expectations of equilibrium isotope fractionation (Morgan $e t$ al., 2010). By this argument, the binding of sFe by very strong Fe-binding ligands could explain its enrichment relative to $\mathrm{cFe}$, which is possibly more loosely associated/trapped inside bulky organics or is inorganic in composition. Alternatively, several other Fe transformations occurring in the surface ocean could favor $\mathrm{sFe}$ or $\mathrm{cFe}$ and fractionate surface $\mathrm{sFe}$ and $\mathrm{cFe}$ isotopes including photoreduction of $\mathrm{Fe}(\mathrm{III})$ to $\mathrm{Fe}(\mathrm{II})$, biological uptake of $\mathrm{dFe}$, and scavenging of Fe onto particles. The potential isotope effects associated with these processes are unknown, and thus we cannot further constrain their possible impact on size fractionated $\delta^{56} \mathrm{Fe}$.

Overall, the Fe isotopic signatures of the sFe fraction support our dFe size partitioning model (Figure 11) that $\mathrm{sFe}$ and $\mathrm{cFe}$ have either different sources or undergo different processes in the upper ocean, while they are sourced by identical remineralization pathways or are isotopically equilibrated by the exchange reactions following remineralization in the subsurface ocean. We also note that while the $\delta^{56} \mathrm{Fe}$ of the bulk dFe was relatively invariant in this dataset (Figure 12), the $\delta^{56} \mathrm{Fe}$ of the $\mathrm{sFe}$ and $\mathrm{cFe}$ phases were more variable and provided new information that could not be derived from $\mathrm{dFe}$ concentration or isotope ratios alone. Thus, $\mathrm{Fe}$ isotopic analysis of the $\mathrm{sFe}$ and $\mathrm{cFe}$ phases appears to be a useful new tool for investigating the sources, cycling, and potentially even the chemical composition of marine $\mathrm{dFe}$.

\subsection{Final thoughts on the physicochemical speciation of $d F e$}

We conclude with a comment on resolving the physical size partitioning of dFe with the chemical composition of dFe. Gledhill and Buck (2012) define these as:

$$
\begin{array}{ll}
\text { Physical partitioning: } & \mathrm{dFe}=\mathrm{sFe}+\mathrm{cFe} \\
\text { Chemical partitioning: } & \mathrm{dFe}=\mathrm{Fe}^{\prime}+\mathrm{FeL}+\mathrm{Fe}_{\text {inert }}
\end{array}
$$


where $\mathrm{dFe}$ is categorized by size into soluble and colloidal phases (as in this study) and by chemical composition as labile inorganic Fe complexes (Fe'), complexes of $\mathrm{Fe}$ to organic ligands labile on the order of hours $(\mathrm{FeL})$, and relatively refractory Fe complexes $\left(\mathrm{Fe}_{\text {inert }}\right)$. Because different analytical methods are used to measure the physical and chemical size partitioning of $\mathrm{dFe}$, it is difficult to reconcile them. However, it is reasonable to assume that Fe' falls entirely into the soluble phase, FeL is found in both soluble and colloidal fractions, and $\mathrm{Fe}_{\text {inert }}$ might encompass both size fractions as well, given the possibility that very strongly-bound FeL complexes of soluble size could appear inert and inorganicallybound colloidal Fe (Fe nanoparticles) would appear refractory by electrochemical speciation techniques.

We raise this distinction because we have hypothesized that in the surface ocean, along Line $\mathrm{W}$, and downstream of TAG, an excess cFe pool exists that does not exchange with the "steady state" partitioned dFe throughout the rest of the North Atlantic Ocean. While we cannot confirm the chemical composition of this $\mathrm{cFe}$ from the observed size partitioning alone, we do know that $\mathrm{dFe}$ in these locations was derived from continental sources and does not appear to exchange with the ambient dFe pools on relevant timescales (see sections 3.1, 3.3.3, and 3.3.4). Thus our data are consistent with a hypothesis that this excess $\mathrm{cFe}$ fraction could be inorganic $\mathrm{cFe}$ that is so small that it remains suspended in the $\mathrm{cFe}$ phase, which is different from the more typical (assumed here organically-bound) $\mathrm{cFe}$ found throughout the rest of GA03 deep waters.

This suggestion of the presence of inorganic cFe is important because different compositional forms of cFe would be likely to undergo different exchange processes at very different rates. In other words, the individual exchange processes between $\mathrm{cFe}$ and $\mathrm{sFe}$ or $\mathrm{pFe}$ in the model of Fig. 10 would potentially be different for inorganic and organically-bound cFe. For example, inorganic cFe may be "inert" to biological processes and even have different exchange rates between the Fe size fractions than typical (organic) marine $\mathrm{dFe}$. Others have previously suggested that nanoparticulate $\mathrm{dFe}$ could be stabilized/trapped inside colloidal-sized organics such as transparent exopolymer compounds (Stolpe and Hassellov, 2010). While an inorganic component to dFe would be no surprise in hydrothermal plumes where nanoparticulate pyrite has already been posited to exist in the dFe size fraction (Yucel et al., 2011), a significant nanoparticulate component of $\mathrm{dFe}$ in the surface ocean or along Line $\mathrm{W}$ would provide an exception to the prevailing view that $>99.9 \%$ of marine $\mathrm{dFe}$ is bound by organic ligands. However, our suggestion of a significant inorganic $\mathrm{cFe}$ pool is consistent with Fe-ligand size partitioning studies in the surface North Atlantic Ocean that report nearly no excess colloidal Fe ligands, despite there being a surface excess of cFe over sFe (Cullen et al., 2006): potentially much of this "inert" cFe is inorganic Fe that does not have an "unbound" ligand pool capable of being analyzed electrochemically.

With the size partitioning data reported here, we cannot confirm an inorganic cFe composition. For confirmation, we look toward future analyses of the cFe phase by synchrotron (similar to von der 
Heyden et al., 2012) and flow-field flow fractionation methods (Stolpe et al., 2010) to resolve the physical and chemical classifications of dFe. Only with this resolution could we justify a refined Fig. 10 model differentiating the exchange reactions and kinetics that unique chemical forms of cFe undergo.

\section{Conclusions}

We sampled 28 stations across the North Atlantic Ocean for the size partitioning of dFe into soluble $(<0.02 \mu \mathrm{m})$ and colloidal $(0.02-0.2 \mu \mathrm{m})$ phases with the highest depth resolution explored to date. Assisted by the multidimensional range of GA03 chemical tracers discussed in this issue and cited throughout this paper, we have reached a new view of dFe partitioning in the North Atlantic Ocean. Previously $\mathrm{dFe}$ was thought to have a constant $\mathrm{sFe}$ component and a more variable cFe component that alone controlled the variability in the observed dFe profile (Bergquist et al., 2007). sFe was believed to be the more "nutrient-like" phase, while cFe had a more dynamic distribution related to new Fe inputs. Following this, we expected to find a relatively uniform sFe concentration in the intermediate and deep North Atlantic Ocean. Instead, we found that both $\mathrm{sFe}$ and $\mathrm{cFe}$ have variable concentrations in the North Atlantic Ocean, and both contribute to $\mathrm{dFe}$ variability nearly equally, which we hypothesize occurs via a "steady state" partitioning driven by constant exchange between the Fe pools following remineralization. We observe a near 50:50\% dFe partitioning into sFe and cFe fractions in the North Atlantic below the deep chlorophyll maximum and a partitioning favoring 60-80\% cFe along Line $\mathrm{W}$. Using a smaller definition of $\mathrm{sFe}(<10 \mathrm{kDa})$, we found a $\sim 65 \%$ partitioning into $\mathrm{cFe}$ along the eastern North Atlantic (2010 stations).

However, several regions of the North Atlantic failed to reach the dFe size partitioning "steady state," either because not enough time had passed for the dFe to reach steady state or because some of the $\mathrm{dFe}$ was not kinetically labile to exchange. The clearest examples of these were the upper ocean, where cFe dominated in the surface ocean underlying the North African dust plume, and in waters in and downstream of the TAG hydrothermal plume. We hypothesize that there may be a significant inorganic cFe component to these continentally-derived Fe sources. In contrast, $\mathrm{cFe}$ disappeared in the deep chlorophyll maximum as a result of increased $\mathrm{cFe}$ biological uptake and/or scavenging/aggregation to the particulate Fe phase in upper ocean waters, after which the remaining dFe did not re-attain steady state size partitioning. Thus, we have found that $\mathrm{sFe}$ and cFe cycle synchronously through much of the North Atlantic ocean, except in the upper ocean and in regions experiencing significant lithogenic $\mathrm{cFe}$ inputs, where $\mathrm{cFe}$ cycles independently of sFe. The suggested constant partitioning of dFe accomplished by Fe exchange between phases was further supported by stable Fe isotope ratios of the sFe and $\mathrm{dFe}$ phases, where $\mathrm{sFe}$ and $\mathrm{dFe}$ had identical $\delta^{56} \mathrm{Fe}$ in the subsurface (connoting successful steady state exchange) but had very different $\delta^{56} \mathrm{Fe}$ in the surface ocean (where sFe and cFe are thought to cycle independently). 
This dFe size partitioning could be incorporated into future models of dFe biogeochemistry in order to better predict Fe limitation and downstream dFe concentrations, since the two size fractions potentially behave uniquely during biouptake and scavenging. We also look forward to future studies that better combine size partitioning techniques with analyses resolving the chemical composition of the $\mathrm{dFe}$ pool in order to better constrain the physicochemical nature of marine $\mathrm{dFe}$. 


\section{Figure Captions}

Figure 1: Station map. Stations from the 2010 cruise are shown in red, and stations from the 2011 cruise are in blue. The TENATSO crossover station was occupied on both cruises (station USGT10-12 and station USGT11-24). The locations of the Line W stations (USGT11-02 through USGT11-08), BATS station (USGT11-10), TAG hydrothermal station (USGT11-16), and the Mauritanian transect (USGT1009 through USGT10-12) are also indicated. Stations from the literature that are referenced in this paper are also indicated as open symbols (Bergquist et al., 2007; Fitzsimmons and Boyle, 2014b).

Figure 2: Sections from the 2011 cruise of (a) dissolved $\mathrm{Fe}<0.2 \mu \mathrm{m}$ analyzed by the $\mathrm{Mg}$ co-precipitation method of $\mathrm{Wu}$ and Boyle (1998), (b) soluble $\mathrm{Fe}<0.02 \mu \mathrm{m}$ analyzed by the NTA method of Lee et al. (2011), (c) colloidal Fe calculated as $\mathrm{dFe}-\mathrm{sFe}$, and (d) \%cFe calculated as $\mathrm{cFe} / \mathrm{dFe}$ (in percent). Station numbers are shown at the bottom of each panel.

Figure 3: Surface dFe partitioning as a function of longitude from (a) the 2011 cruise and (b) the 2010 cruise. Station numbers are indicated at the top. Colloidal Fe can be calculated as dFe minus sFe. Recall that $\mathrm{sFe}$ is defined as $<0.02 \mu \mathrm{m}$ in (a) and $<10 \mathrm{kDa}$ in (b). In (b), the gray points at $-22^{\circ} \mathrm{W}$ are from USGT10-07, which lies somewhat north of the other three stations indicated (Mauritanian transect USGT10-10 through USGT10-12). Error bars show \pm 1 standard deviation error on analytical replicates.

Figure 4: The speciation and size distribution of dissolved Fe in the upper 200m on (a-c) the 2011 cruise where $\mathrm{sFe}$ is defined as $<0.02 \mu \mathrm{m}$ and on (d-e) the 2010 cruise where $\mathrm{sFe}$ is defined as $<10 \mathrm{kDa}$. The deep chlorophyll maximum (DCM) is designated as the fluorescence maximum in grey. Note that colloidal Fe (dFe minus sFe) goes to zero at the DCM, except along the western North Atlantic margin (a: USGT1106). Not surprisingly, the DCM also appears to be a depth of maximum particle loading at many stations, as the light transmission shows a coincident minimum with the DCM (f: USGT10-09, as an example).

Figure 5: dFe partitioning resulting from remineralization in the Central Water layer (potential density 25.8-27.1 kg/m ${ }^{3}$ ), shown as a function of apparent oxygen utilization (AOU) for (a) Line W USGT11-03 to -08 where the sFe size cutoff is $0.02 \mu \mathrm{m}$, (b) the subtropical gyre stations USGT11-10 to -24 where the sFe size cutoff is $0.02 \mu \mathrm{m}$, and (c) the 2010 cruise stations USGT10-07 to -12 where the sFe size cutoff is $10 \mathrm{kDa}$. Samples are only utilized in these regressions if they are below the DCM and away from external Fe sources (margin and hydrothermal stations are removed). Filled circles show $\mathrm{dFe}(<0.2 \mu \mathrm{m})$, open circles show $\mathrm{sFe}(<0.02 \mu \mathrm{m}$ in $\mathrm{a}-\mathrm{b},<10 \mathrm{kDa}$ in $\mathrm{c})$, and crosses show $\mathrm{cFe}$ (dFe minus $\mathrm{sFe})$. Fe: $\mathrm{C}$ values (in 
units of $\mu \mathrm{mol} / \mathrm{mol}$ ) are calculated from the Type-I regressions shown using an AOU:C ratio of 1.6 (Martin et al., 1987). Errors are \pm 1 standard error from the calculated regression slope.

Figure 6: Full-depth ocean profiles of dissolved $\mathrm{Fe}(<0.2 \mu \mathrm{m}$, closed circles $)$ and soluble $\mathrm{Fe}(<0.02 \mu \mathrm{m}$ in a-c and $<10 \mathrm{kDa}$ in d). Station locations are (a) USGT11-06 with the transmissometry trace, (b) USGT11-12 with the silicate trace, (c) USGT11-20 with the silicate trace, and (d) USGT10-09 with the oxygen trace.

Figure 7: Sections from the 2010 cruise along the Mauritanian transect of (a) dissolved Fe $<0.2 \mu \mathrm{m}$, (b) soluble $\mathrm{Fe}<0.02 \mu \mathrm{m}$, (c) colloidal Fe calculated as dFe-sFe, and (d) \%cFe calculated as cFe/dFe. Station numbers are shown at the bottom of each panel.

Figure 8: A comparison of dFe size partitioning during the two years of cruises at TENATSO. (a) dFe $(<0.2 \mu \mathrm{m})$ over the two years with the oxygen shown in gray to designate the OMZ. (b) sFe over the two years, with the 2010 sampling occurring by CFF $(<10 \mathrm{kDa})$ and the 2011 sampling occurring by Anopore filtration $(<0.02 \mu \mathrm{m})$. (c) cFe over the two years, as $\mathrm{cFe}=\mathrm{dFe}-\mathrm{sFe}$. (d) A ratio of the $2010 \mathrm{sFe}$ collected by CFF divided by the $2011 \mathrm{sFe}$ collected by Anopore filtration. Depths where this ratio is particularly low indicate depths where there is a significant component of $\mathrm{dFe}$ in the $10 \mathrm{kDa}-0.02 \mu \mathrm{m}$ size fraction. The dotted line at 70m is the DCM, and the shaded region includes depths where the dissolved oxygen concentration is $<100 \mu \mathrm{mol} / \mathrm{kg}$ (the OMZ). Error bars indicate \pm 1 standard deviation in replicate analyses of the same sample.

Figure 9: dFe size partitioning at (a) station USGT11-14, which is $\sim 500 \mathrm{~km}$ to the northwest of the TAG site, and (b-c) station USGT11-16, the TAG site (note the much larger dFe scale in panel c). Colloidal Fe (cFe) can be taken as the difference between $\mathrm{dFe}$ and sFe at any depth. In (c), the grey line shows the transmissometer trace, where a drop in the signal designates light absorption by enhanced particles in the water column. In the portion of the water column influenced by hydrothermal venting, sFe comprises 9$18 \%$ of the dFe at USGT11-14 compared to only 4-11\% of the dFe at TAG USGT11-16.

Figure 10: Relationships between $\mathrm{dFe}, \mathrm{sFe}$, and cFe in (a) Bergquist et al. (2007), (b) Fitzsimmons and Boyle (2014b), (c) Line W stations USGT11-02 through USGT11-08, (d) North Atlantic subtropical gyre stations USGT11-10 through USGT11-22, and (e) stations USGT10-05 through USGT10-12 from the 2010 eastern North Atlantic cruise including the Mauritanian/OMZ section. In panels c-e, depths below 
the DCM are shown as filled circles and are included in the regressions, while depths at and above the DCM are shown as open circles and are not included in the regressions. Station USGT11-16 is excluded altogether, as are the TAG-influenced depths at Station USGT11-14. Regressions are Type-II, and in (a) the statistics are taken from Bergquist et al. (2007). The dashed line on the right panels shows the 1:1 $\mathrm{sFe}: \mathrm{cFe}$ line.

Figure 11: Model of Fe size partitioning, focused on the processes controlling dFe partitioning into soluble and colloidal fractions (box size has no relation to relative Fe pool size in this figure) for (a) the subsurface ocean (below the deep chlorophyll maximum) and (b) the upper ocean (surface through the deep chlorophyll maximum). Measurable quantities are shown in the gray rectangles ( $\mathrm{sFe}, \mathrm{cFe}, \mathrm{dFe}, \mathrm{pFe}$ ), and exchange rates are shown as arrows. The black arrows and bolded processes indicate the mechanism(s) driving the dominant partitioning pattern expressed in the partitioning plots of Figure 10 for each depth range.

Figure 12: Size partitioned dFe concentration and stable isotope ratio $\left(\delta^{56} \mathrm{Fe}\right)$ at (a) USGT11-11 near Bermuda and (b) USGT11-21 (at the surface) and USGT11-23 (at $475 \mathrm{~m}$ ). dFe $(<0.2 \mu \mathrm{m}$ ) is shown with filled circles and solid lines, $\mathrm{sFe}(<10 \mathrm{kDa})$ is shown with open circles and dashed lines, and $\mathrm{cFe}(10 \mathrm{kDa}$ $<\mathrm{cFe}<0.2 \mu \mathrm{m})$ is shown as crosses and was calculated as $\mathrm{dFe}-\mathrm{sFe}$ and by isotope mass balance. The dissolved oxygen CTD trace is indicated in gray for USGT11-11 and USGT11-23.

\begin{tabular}{|c|c|c|c|c|}
\hline Parameter or SRM & Consensus [Fe] & [dFe] & 2010 [sFe] & 2011 [sFe] \\
\hline Procedure blank range & -- & $\begin{array}{c}0.078 \pm 0.008 \\
(n=11 \text { sessions) }\end{array}$ & $\begin{array}{c}0.009-0.019 \\
\text { ( } n=11 \text { sessions) }\end{array}$ & $\begin{array}{c}0.006-0.026 \\
(n=18 \text { sessions) }\end{array}$ \\
\hline Detection limit $(3 \sigma)$ & -- & $0.03-0.05$ & 0.027 & 0.030 \\
\hline SAFe D2 & $0.933 \pm 0.032$ & $0.950 \pm 0.035$ & $\begin{array}{l}0.931 \pm 0.046 \\
(\# 446, n=28)\end{array}$ & $\begin{array}{l}0.930 \pm 0.042 \\
(\# 446, n=43)\end{array}$ \\
\hline $\begin{array}{c}\text { SAFe surface underway } \\
\text { (Boyle-lab internal standard) }\end{array}$ & $\begin{array}{c}0.093 \pm 0.008 \\
\text { (assume SAFe S) }\end{array}$ & -- & $\begin{array}{c}0.083 \pm 0.035 \\
(n=39)\end{array}$ & $\begin{array}{c}0.079 \pm 0.050 \\
(n=73)\end{array}$ \\
\hline SAFe S & $0.093 \pm 0.008$ & $0.103 \pm 0.010$ & 1. & $\begin{array}{c}0.094 \pm 0.006 \\
(\# 16, n=3) \\
0.108 \pm 0.002 \\
(\# 318, n=3)\end{array}$ \\
\hline
\end{tabular}

Table 1: Reported procedure blanks, detection limits, and comprehensive lab analyses of the SAFe standard reference materials over the analytical sessions. dFe concentrations were analyzed in the $\mathrm{Wu}$ laboratory at RSMAS by the method described in Wu and Boyle (1998). sFe concentrations were 
analyzed in the Boyle laboratory at MIT by the methods described in Lee et al. (2011). All Fe concentrations are in units of $\mathrm{nmol} / \mathrm{kg}$, and consensus values are taken from http://www.geotraces.org/science/intercalibration as of May 2013. The detection limit is calculated as three times the standard deviation of the procedure blank for each analytical session.

\begin{tabular}{|c|c|c|c|c|c|c|c|}
\hline \multirow[b]{2}{*}{ Year } & \multirow[b]{2}{*}{ Stations } & \multicolumn{2}{|c|}{ Dissolved Fe } & \multicolumn{2}{|c|}{ Soluble Fe } & \multirow{2}{*}{$\begin{array}{c}\text { \%sFe } \\
\text { REMIN } \\
\text { dFe:C / } \\
\text { dFe:C }\end{array}$} & \multirow{2}{*}{$\begin{array}{c}\% s F e_{\mathrm{pF}} \\
\text { Pre-formed } \\
\text { sFe/dFe }\end{array}$} \\
\hline & & $\begin{array}{c}\text { dFe:C } \\
(\mu \mathrm{mol} / \mathrm{mol})\end{array}$ & $\begin{array}{c}\text { Pre-formed } \\
\text { dFe } \\
\text { (nmol/kg) }\end{array}$ & $\begin{array}{c}\text { sFe:C } \\
(\mu \mathrm{mol} / \mathrm{mol})\end{array}$ & $\begin{array}{c}\text { Pre-formed } \\
\text { sFe } \\
\text { (nmol/kg) }\end{array}$ & & \\
\hline 2010 & $7,11,12$ & $5.49 \pm 0.82$ & $0.45 \pm 0.08$ & $2.26 \pm 1.06$ & $0.16 \pm 0.10$ & $41 \pm 25 \%$ & $35 \pm 29 \%$ \\
\hline \multirow{2}{*}{2011} & Line $\mathrm{W}: 3-8$ & $5.69 \pm 1.30$ & $0.26 \pm 0.04$ & $2.49 \pm 0.69$ & $0.07 \pm 0.02$ & $44 \pm 22 \%$ & $27 \pm 13 \%$ \\
\hline & Gyre: $10-22$ & $6.02 \pm 0.66$ & $0.20 \pm 0.03$ & $2.83 \pm 0.36$ & $0.11 \pm 0.01$ & $47 \pm 11 \%$ & $57 \pm 15 \%$ \\
\hline
\end{tabular}

Table 2: $\mathrm{dFe}: \mathrm{C}$ and $\mathrm{sFe}: \mathrm{C}$ relationships (in $\mu \mathrm{mol} / \mathrm{mol}$ ) and pre-formed $\mathrm{dFe}$ and $\mathrm{sFe}$ (in $\mathrm{nmol} / \mathrm{kg}$ ) Central Waters below the DCM in the potential density range $25.8-27.1 \mathrm{~kg} / \mathrm{m}^{3}$ (largely dominated by North Atlantic Central Water, with smaller contributions of Atlantic Equatorial Water, and Southwest Atlantic Central Water, Jenkins et al., this issue). The $\% \mathrm{sFe}_{\mathrm{REMIN}}$ (\% soluble Fe attributed to remineralization) is calculated as the ratio of $\mathrm{sFe}: \mathrm{C}$ to $\mathrm{dFe}: \mathrm{C}$ (ignores the partitioning contribution by pre-formed $\mathrm{dFe}$ ). The $\% \mathrm{sFe}_{\mathrm{PF}}$ attributed to pre-formed $\mathrm{dFe}$ is calculated as the ratio of pre-formed $\mathrm{sFe}$ to pre-formed $\mathrm{dFe}$ (ignores the partitioning contribution by remineralization). Fe:C values are calculated from a Type-I regression of $\mathrm{Fe}$ and $\mathrm{AOU}$, and the $\mathrm{Fe}: \mathrm{AOU}$ slope was converted to an $\mathrm{Fe}: \mathrm{C}$ using the AOU:C ratio of 1.6 (Martin et al., 1987). Error values are \pm 1 standard error from the calculated regression.

\section{References}

Aguilar-Islas, A.M., Wu, J., Rember, R., Johansen, A.M., Shank, L.M., 2010. Dissolution of aerosol-derived iron in seawater: Leach solution chemistry, aerosol type, and colloidal iron fraction. Marine Chemistry 120 (1-4), 25-33.

Barbeau, K., Moffett, J.W., Caron, D.A., Croot, P.L., Erdner, D.L., 1996. Role of protozoan grazing in relieving iron limitation of phytoplankton. Nature 380, 61-64.

Beard, B.L., Johnson, C.M., Von Damm, K.L., Poulson, R.L., 2003. Iron isotope constraints on Fe cycling and mass balance in oxygenated Earth oceans. Geology 31 (7), 629-632.

Bennett, S.A., Achterberg, E.P., Connelly, D.P., Statham, P.J., Fones, G.R., German, C.R., 2008. The distribution and stabilisation of dissolved Fe in deep-sea hydrothermal plumes. Earth and Planetary Science Letters 270, 157-167.

Bergquist, B.A., Boyle, E.A., 2006. Dissolved iron in the tropical and subtropical Atlantic Ocean. Global Biogeochemical Cycles 20 (1), 14. 
Bergquist, B.A., Wu, J., Boyle, E.A., 2007. Variability in oceanic dissolved iron is dominated by the colloidal fraction. Geochimica Et Cosmochimica Acta 71 (12), 2960-2974.

Bhatia, M.P., Kujawinski, E.B., Das, S.B., Breier, C.F., Henderson, P.B., Charette, M.A., 2013. Greenland meltwater as a significant and potentially bioavailable source of iron to the ocean. Nature Geoscience 6 (4), 274-278.

Bower, A., Lozier, S., Gary, S., 2011. Export of Labrador Sea Water from the subpolar North Atlantic: A Lagrangian perspective. Deep Sea Research Part II: Topical Studies in Oceanography 58 (17-18), 17981818.

Bower, A.S., Lozier, M.S., Gary, S.F., Boning, C.W., 2009. Interior pathways of the North Atlantic meridional overturning circulation. Nature 459 (7244), 243-247.

Boye, M., Nishioka, J., Croot, P., Laan, P., Timmermans, K.R., Strass, V.H., Takeda, S., de Baar, H.J.W., 2010. Significant portion of dissolved organic Fe complexes in fact is Fe colloids. Marine Chemistry 122 (1-4), 20-27.

Boyle, E.A., Jenkins, W.K., 2008. Hydrothermal iron in the deep western South Pacific. Geochimica Et Cosmochimica Acta 72, A107.

Brewer, P.G., Spencer, D.W., Biscaye, P.E., Hanley, A., Sachs, P.L., Smith, C.L., Kadar, S., Fredericks, J., 1976. The distribution of particulate matter in the Atlantic Ocean. Earth and Planetary Science Letters 32 (2), 393-402.

Charette, M.A., Morris, P.J., Henderson, P.B., Moore, W.S., this issue. Radium isotopes as tracers of boundary exchange processes along the US GETORACES North Atlantic Zonal Transect. Deep-Sea Research II U.S. GEOTRACES North Atlantic Special Issue.

Chen, M., Dei, R.C.H., Wang, W.-X., Guo, L., 2003. Marine diatom uptake of iron bound with natural colloids of different origins. Marine Chemistry 81 (3-4), 177-189.

Chen, M., Wang, W.X., 2001. Bioavailability of natural colloid-bound iron to marine plankton: Influences of colloidal size and aging. Limnology \& Oceanography 46 (8), 1956-1967.

Chever, F., Bucciarelli, E., Sarthou, G., Speich, S., Arhan, M., Penven, P., Tagliabue, A., 2010. Physical speciation of iron in the Atlantic sector of the Southern Ocean along a transect from the subtropical domain to the Weddell Sea Gyre. Journal of Geophysical Research 115 (C10), C10059.

Chiba, H., Masuda, H., Lee, S., Y, Fujioka, K., 2001. Chemistry of hydrothermal fluids at the TAG Active Mound, MAR 26 N, in 1998. Geophysical Research Letters 28 (15), 2919-2922.

Conway, T.M., John, S.G., 2014. Quantification of sources of dissolved iron to the North Atlantic Ocean. Nature 511, 212-215.

Conway, T.M., Rosenberg, A.D., Adkins, J.F., John, S.G., 2013. A new method for precise determination of iron, zinc, and cadmium stable isotope ratios in seawater by double-spike mass spectrometry.

Analytica Chimica Acta 793, 44-52.

Croot, P.L., Streu, P., Baker, A.R., 2004. Short residence time for iron in surface seawater impacted by atmospheric dry deposition from Saharan dust events. Geophysical Research Letters 31 (23), L23S08. Cullen, J.T., Bergquist, B.A., Moffett, J.W., 2006. Thermodynamic characterization of the partitioning of iron between soluble and colloidal species in the Atlantic Ocean. Marine Chemistry 98 (2-4), 295-303.

Cutter, G.A., Bruland, K.W., 2012. Rapid and noncontaminating sampling system for trace elements in a global ocean surveys. Limnology \& Oceanography: Methods 10, 425-436.

Dideriksen, K., Baker, J.A., Stipp, S.L.S., 2008. Equilibrium Fe isotope fractionation between inorganic aqueous Fe(III) and the siderophore complex, Fe(III)-desferrioxamine B. Earth and Planetary Science Letters 269, 280-290.

Field, M.P., Sherrell, R.M., 2000. Dissolved and particulate Fe in a hydrothermal plume at $9^{\circ} 45^{\prime} N$, East Pacific Rise: Slow Fe (II) oxidation kinetics in Pacific plumes. Geochimica Et Cosmochimica Acta 64 (4), 619-628. 
Fitzsimmons, J.N., Boyle, E.A., 2012. An intercalibration between the GEOTRACES GO-FLO and the MITESS/Vanes sampling systems for dissolved iron concentration analyses (and a closer look at adsorption effects). Limnology \& Oceanography: Methods 10, 437-450.

Fitzsimmons, J.N., Boyle, E.A., 2014a. Assessment and comparison of Anopore and cross flow filtration methods for the determination of dissolved iron size fractionation into soluble and colloidal phases in seawater. Limnology \& Oceanography: Methods 12, 244-261.

Fitzsimmons, J.N., Boyle, E.A., 2014b. Both soluble and colloidal iron phases control dissolved iron variability in the tropical North Atlantic Ocean. Geochimica et Cosmochimica Acta 125, 539-550.

Fitzsimmons, J.N., Bundy, R.M., Al-Subiai, S.N., Barbeau, K.A., Boyle, E.A., in press. The composition of dissolved iron in the dusty surface ocean: An exploration using size-fractionated iron-binding ligands.

Marine Chemistry.

Fitzsimmons, J.N., Jenkins, W.J., Boyle, E.A., 2014. Distal transport of dissolved hydrothermal iron in the deep South Pacific Ocean. Proceedings of the National Academy of Sciences.

Fitzsimmons, J.N., Zhang, R., Boyle, E.A., 2013. Dissolved iron in the tropical North Atlantic oxygen minimum zone. Marine Chemistry 154, 87-99.

Gledhill, M., Buck, K.N., 2012. The organic complexation of iron in the marine environment: a review. Frontiers in Microbiology 3, 69.

Gross, T.F., Williams, A.J., Newell, A.R.M., 1988. A deep-sea sediment transport storm. Nature 331 (6156), 518-521.

Hall, I.R., Measures, C.I., 1998. The distribution of Al in the IOC stations of the North Atlantic and Norwegian Sea between $52^{\circ}$ and $65^{\circ}$ North. Marine Chemistry 61, 69-85.

Hassler, C.S., Alasonati, E., Mancuso Nichols, C.A., Slaveykova, V.I., 2011a. Exopolysaccharides produced by bacteria isolated from the pelagic Southern Ocean: Role in Fe binding, chemical reactivity, and bioavailability. Marine Chemistry 123, 88-98.

Hassler, C.S., Schoemann, V., 2009. Bioavailability of organically bound Fe to model phytoplankton of the Southern Ocean. Biogeosciences 6 (10), 2281-2296.

Hassler, C.S., Schoemann, V., Nichols, C.M., Butler, E.C.V., Boyd, P.W., 2011b. Saccharides enhance iron bioavailability to Southern Ocean phytoplankton. Proceedings of the National Academy of Sciences 108 (3), 1076-1081.

Hatta, M., Measures, C.I., Roshan, S., Wu, J., Fitzsimmons, J.N., Sedwick, P., Morton, P.L., this issue. An overview of dissolved Fe and Mn distributions during hte 2010-2011 U.S. GEOTRACES North Atlantic cruises. Deep-Sea Research II U.S. GEOTRACES North Atlantic Special Issue.

Homoky, W.B., John, S.G., Conway, T.M., Mills, R.A., 2013. Distinct iron isotopic signatures and supply from marine sediment dissolution. Nature Communications 4, 2143.

Honeyman, B.D., Santschi, P.H., 1989. A Brownian-pumping model for oceanic trace metal scavenging: Evidence from Th isotopes. Journal of Marine Research 47, 951-992.

Hutchins, D.A., Witter, A.E., Butler, A., Luther III., G.W., 1999. Competition among marine phytoplankton for different chelated iron species. Nature 400, 858-861.

Ilina, S.M., Poitrasson, F., Lapitskiy, S.A., Alekhin, Y.V., Viers, J., Pokrovsky, O.S., 2013. Extreme iron isotope fractionation between colloids and particles of boreal and temperate organic-rich waters. Geochimica et Cosmochimica Acta 101, 96-111.

James, R.H., Elderfield, H., 1996. Dissolved and particulate trace metals in hydrothermal plumes at the Mid-Atlantic Ridge. Geophysical Research Letters 23 (23), 3499-3502.

Jenkins, W.J., Smethie, W.M., Boyle, E.A., Cutter, G.A., this issue. Water Mass Analysis for the U.S. GEOTRACES North Atlantic Sections. Deep-Sea Research II U.S. GEOTRACES North Atlantic Special Issue. Jickells, T.D., An, Z.S., Andersen, K.K., Baker, A.R., Bergametti, G., Brooks, N., Cao, J.J., Boyd, P.W., Duce, R.A., Hunter, K.A., Kawahata, H., Kubilay, N., laRoche, J., Liss, P.S., Mahowald, N., Prospero, J.M., 
Ridgwell, A.J., Tegen, I., Torres, R., 2005. Global iron connections between desert dust, ocean biogeochemistry, and climate. Science 308 (5718), 67-71.

John, S.G., 2012. Optimizing sample and spike concentrations for isotopic analysis by double-spike ICPMS. Journal of Analytical Atomic Spectrometry 27 (12), 2123-2131.

John, S.G., Adkins, J., 2012. The vertical distribution of iron stable isotopes in the North Atlantic near Bermuda. Global Biogeochem. Cycles 26 (2), GB2034.

John, S.G., Mendez, J., Moffett, J., Adkins, J., 2012. The flux of iron and iron isotopes from San Pedro Basin sediments. Geochimica Et Cosmochimica Acta 93, 14-29.

Johnson, K.S., Gordon, R.M., Coale, K.H., 1997. What controls dissolved iron concentrations in the world ocean? Marine Chemistry 57 (3-4), 137-161.

Joyce, T.M., Dunworth-Baker, J., Pickart, R.S., Torres, D., Waterman, S., 2005. On the Deep Western Boundary Current south of Cape Cod. Deep-Sea Research II 52, 615-625.

Kieber, R.J., Skrabal, S.A., Smith, B.J., Willey, J.D., 2005. Organic Complexation of Fe(II) and Its Impact on the Redox Cycling of Iron in Rain. Environmental Science and Technology 39 (6), 1576-1583.

Lacan, F., Radic, A., Jeandel, C., Poitrasson, F., Sarthou, G., Pradoux, C., Freydier, R., 2008. Measurement of the isotopic composition of dissolved iron in the open ocean. Geophysical Research Letters 35 (24), 5. Lannuzel, D., Schoemann, V.r., de Jong, J., Tison, J.-L., Chou, L., 2007. Distribution and biogeochemical behaviour of iron in the East Antarctic sea ice. Marine Chemistry 106 (1-2), 18-32.

Lee, J.-M., Boyle, E.A., Echegoyen-Sanz, Y., Fitzsimmons, J.N., Zhang, R., Kayser, R.A., 2011. Analysis of trace metals $(\mathrm{Cu}, \mathrm{Cd}, \mathrm{Pb}$, and $\mathrm{Fe}$ ) in seawater using single batch Nitrilotriacetate resin extraction and isotope dilution inductively coupled plasma mass spectrometry. Analytica Chimica Acta 686, 93-101. Mahowald, N., Baker, A.R., Bergametti, G., Brooks, N., Duce, R.A., Jickells, T., Kubilay, N., Prospero, J.M., Tegen, I., 2005. Atmospheric global dust cycle and iron inputs to the ocean. Global Biogeochemical Cycles 19, GB4025.

Martin, J.H., Knauer, G.A., Karl, D.M., Broenkow, W.W., 1987. VERTEX: carbon cycling in the northeast Pacific. Deep Sea Research Part A. Oceanographic Research Papers 34 (2), 267-285.

McCartney, M.S., 1992. Recirculating components to the deep boundary current of the northern North Atlantic. Progress In Oceanography 29, 283-383.

Measures, C.I., Hatta, M., Fitzsimmons, J.N., Morton, P.L., this issue. Dissolved Al in the zonal N Atlantic section of the US GETORACES 2010/2011 cruises and the importance of hydrothermal inputs. Deep-Sea Research II U.S. GEOTRACES North Atlantic Special Issue.

Measures, C.I., Landing, W.M., Brown, M.T., Buck, C.S., 2008. High-resolution Al and Fe data from the Atlantic Ocean CLIVAR- $\mathrm{CO}_{2}$ Repeat Hydrography A16N transect: Extensive linkages between atmospheric dust and upper ocean geochemistry. Global Biogeochem. Cycles 22, GB1005.

Moore, J.K., Doney, S.C., Glover, D.M., Fung, I.Y., 2002. Iron cycling and nutrient-limitation patterns in surface waters of the World Ocean. Deep Sea Research Part II: Topical Studies in Oceanography 49 (1-3), 463-507.

Morel, F.M.M., Milligan, A.J., Saito, M.A., 2003. Marine Bioinorganic Chemistry: The Role of Trace Metals in the Oceanic Cycles of Major Nutrients. In: Turekian, K.K., Holland, H.D. (Eds.), Treatise On Geochemistry. Elsevier Science Ltd., Cambridge, United Kingdom, pp. 113-143.

Morgan, J.L.L., Wasylenki, L.E., Nuester, J., Anbar, A.D., 2010. Fe isotope fractionation during equilibration of Fe-organic complexes. Environmental Science \& Technology 44 (16), 6095-6101.

Nishioka, J., Obata, H., Tsumune, D., 2013. Evidence of an extensive spread of hydrothermal dissolved iron in the Indian Ocean. Earth and Planetary Science Letters 361, 26-33.

Nishioka, J., Takeda, S., Wong, C.S., 2001a. Change in the concentrations of iron in different size fractions during a phytoplankton bloom in controlled ecosystem enclosures. Journal of Experimental Marine Biology and Ecology 258 (2), 237-255. 
Nishioka, J., Takeda, S., Wong, C.S., Johnson, W.K., 2001b. Size-fractionated iron concentrations in the northeast Pacific Ocean: distribution of soluble and small colloidal iron. Marine Chemistry 74 (2-3), 157179.

Ohnemus, D.C., Lam, P.J., this issue. Cycling of lithogenic marine particulates in the U.S. GEOTRACES North Atlantic Zonalo Transect. Deep-Sea Research II U.S. GEOTRACES North Atlantic Special Issue. Radic, A., Lacan, F., Murray, J.W., 2011. Iron isotopes in the seawater of the equatorial Pacific Ocean: New constraints for the oceanic iron cycle. Earth and Planetary Science Letters 306, 1-10.

Revels, B.N., Ohnemus, D.C., Lam, P.J., Conway, T.M., John, S.G., this issue. The isotopic signature and distribution of particulate iron in the North Atlantic Ocean. Deep-Sea Research II U.S. GEOTRACES North Atlantic Special Issue.

Rich, H.W., Morel, F.M.M., 1990. Availability of well-defined iron colloids to the marine diatom Thalassiosira weissflogii. Limnology \& Oceanography 35 (3), 652-662.

Rijkenberg, M.J.A., Powell, C.F., Dall'Osto, M., Nielsdottir, M.C., Patey, M.D., Hill, P.G., Baker, A.R., Jickells, T.D., Harrison, R.M., Achterberg, E.P., 2008. Changes in iron speciation following a Saharan dust event in the tropical North Atlantic Ocean. Marine Chemistry 110 (1-2), 56-67.

Rijkenberg, M.J.A., Steigenberger, S., Powell, C.F., Haren, H.v., Patey, M.D., Baker, A.R., Achterberg, E.P., 2012. Fluxes and distribution of dissolved iron in the eastern (sub-) tropical North Atlantic. Global Biogeochemical Cycles 26, GB3004.

Rona, P.A., Klinkhammer, G., Nelsen, T.A., Trefry, J.H., Elderfield, H., 1986. Black smokers, massive sulphides and vent biota at the Mid-Atlantic Ridge. Nature 321 (6065), 33-37.

Roy, E.G., Wells, M.L., 2011. Evidence for regulation of Fe(II) oxidation by organic complexing ligands in the Eastern Subarctic Pacific. Marine Chemistry 127, 115-122.

Roy, E.G., Wells, M.L., King, D.W., 2008. Persistence of iron(II) in surface waters of the western subarctic Pacific. Limnology \& Oceanography 53 (1), 89-98.

Rue, E.L., Bruland, K.W., 1995. Complexation of iron(III) by natural organic ligands in the Central North Pacific as determined by a new competitive ligand equilibration/adsorptive cathodic stripping voltammetric method. Marine Chemistry 50 (1-4), 117-138.

Saito, M.A., Noble, A.E., Tagliabue, A., Goepfert, T.J., Lamborg, C.H., Jenkins, W.J., 2013. Slow-spreading submarine ridges in the South Atlantic as a significant oceanic iron source. Nature Geoscience 6, 775779.

Scholz, F., Hensen, C., Severmann, S., Noffke, A., Haley, B., McManus, J., Schneider, R., Wallmann, K., 2012. Spatial and temporal trends of iron and iron isotope cycling in the Peruvian Oxygen Minimum Zone. Mineralogical Magazine 76 (6), 2343.

Sedwick, P.N., Sohst, B.M., Bowie, A.R., this issue. A zonal picture of the water column distribution of dissolved iron(II) during the U.S. GEOTRACES North Atlantic cruises. Deep-Sea Research II U.S.

GEOTRACES North Atlantic Special Issue.

Shelley, R.U., Morton, P.L., Landing, W., this issue. Elemental composition of North Atlantic aerosols (US GEOTRACES). Deep-Sea Research II U.S. GEOTRACES North Atlantic Special Issue.

Siebert, C., Nägler, T.F., Kramers, J.D., 2001. Determination of molybdenum isotope fractionation by double-spike multicollector inductively coupled plasma mass spectrometry. Geochemistry, Geophysics, Geosystems 2 (7), 1032.

Stolpe, B., Guo, L., Shiller, A.M., Hassellöv, M., 2010. Size and composition of colloidal organic matter and trace elements in the Mississippi River, Pearl River and the northern Gulf of Mexico, as characterized by flow field-flow fractionation. Marine Chemistry 118 (3-4), 119-128.

Stolpe, B., Hassellov, M., 2010. Nanofibrils and other colloidal biopolymers binding trace elements in coastal seawater: Significance for variations in element size distributions. Limnology \& Oceanography 55 (1), 187-202. 
Stumm, W., Morgan, J.J., 1996. Aquatic Chemistry: Chemical Equilibria and Rates in Natural Waters. John Wiley \& Sons, New York.

Sunda, W.G., 2012. Feedback interactions between trace metal nutrients and phytoplankton in the ocean. Frontiers in Microbiology 3, 204.

Sunda, W.G., Huntsman, S.A., 1997. Interrelated influence of iron, light and cell size on marine phytoplankton growth. Nature 390, 389-392.

Tagliabue, A., Bopp, L., Dutay, J.-C., Bowie, A.R., Chever, F., Jean-Baptiste, P., Bucciarelli, E., Lannuzel, D., Remenyi, T., Sarthou, G., Aumont, O., Gehlen, M., Jeandel, C., 2010. Hydrothermal contribution to the oceanic dissolved iron inventory. Nature Geoscience 3 (4), 252-256.

Taguchi, S., DiTullio, G.R., Laws, E.A., 1988. Physiological characteristics and production of mixed layer and chlorophyll maximum phytoplankton populations in the Caribbean Sea and western Atlantic Ocean. Deep Sea Research Part A. Oceanographic Research Papers 35 (8), 1363-1377.

Talley, L.D., McCartney, M.S., 1982. Distribution and circulation of Labrador Sea Water. Journal of Physical Oceanography 12, 1189-1205.

Taylor, S.R., McLennan, S.M., 1985. The Continental Crust: Its Composition and Evolution. Blackwell, Malden, MA.

Thuróczy, C.E., Gerringa, L.J.A., Klunder, M.B., Middag, R., Laan, P., Timmermans, K.R., de Baar, H.J.W., 2010. Speciation of Fe in the Eastern North Atlantic Ocean. Deep Sea Research Part I: Oceanographic Research Papers 57 (11), 1444-1453.

Toner, B.M., Fakra, S.C., Manganini, S.J., Santelli, C.M., Marcus, M.A., Moffett, J., Rouxel, O., German, C.R., Edwards, K.J., 2009. Preservation of iron(II) by carbon-rich matrices in a hydrothermal plume.

Nature Geoscience 2 (3), 197-201.

Toner, B.M., Marcus, M.A., Edwards, K.J., Rouxel, O., German, C.R., 2012. Measuring the form of iron in hydrothermal plume particles. Oceanography 25 (1), 209-212.

Ussher, S.J., Achterberg, E.P., Sarthou, G., Laan, P., de Baar, H.J.W., Worsfold, P.J., 2010. Distribution of size fractionated dissolved iron in the Canary Basin. Marine Environmental Research 70 (1), 46-55.

van den Berg, C.M.G., 1995. Evidence for organic complexation of iron in seawater. Marine Chemistry 50 (1-4), 139-157.

von der Heyden, B.P., Roychoudhury, A.N., Mtshali, T.N., Tyliszczak, T., Myneni, S.C.B., 2012. Chemically and Geographically Distinct Solid-Phase Iron Pools in the Southern Ocean. Science 338 (6111), 1199-

1201.

Waeles, M., Baker, A.R., Jickells, T., Hoogewerff, J., 2007. Global dust teleconnections: aerosol iron solubility and stable isotope composition. Environmental Chemistry 4 (4), 233-237.

Wang, W.X., Dei, R.C.H., 2003. Bioavailability of iron complexed with organic colloids to the cyanobacteria Synechococcus and Trichodesmium. Aquatic Microbial Ecology 33, 247-259.

Wells, M.L., Goldberg, E.D., 1992. Marine submicron particles. Marine Chemistry 40, 5-18.

Wells, M.L., Goldberg, E.D., 1994. The distribution of colloids in the North Atlantic and Southern Oceans. Limnology \& Oceanography 39 (2), 286-302.

Willey, J.D., Kieber, R.J., Seaton, P.J., Miller, C., 2008. Rainwater as a source of Fe(II)-stabilizing ligands to seawater. Limnology \& Oceanography 53 (4), 1678-1684.

$\mathrm{Wu}$, J., Boyle, E.A., 1998. Determination of iron in seawater by high-resolution isotope dilution inductively coupled plasma mass spectrometry after $\mathrm{Mg}(\mathrm{OH}) 2$ coprecipitation. Analytica Chimica Acta 367 (1-3), 183-191.

Wu, J., Boyle, E.A., Sunda, W.G., Wen, L., 2001. Soluble and colloidal iron in the oligotrophic North Atlantic and North Pacific. Science 293, 847-849.

$\mathrm{Wu}$, J., Luther, G.W., 1995. Complexation of Fe(III) by natural organic ligands in the Northwest Atlantic Ocean by a competitive ligand equilibration method and a kinetic approach. Marine Chemistry 50 (1-4), 159-177. 
Wu, J., Roshan, S., Hatta, M., Measures, C.I., Buck, K.N., this issue. Dissolved Fe enrichment in the oxygen minimum zone of the eastern tropical North Atlantic Ocean. Deep-Sea Research II U.S. GEOTRACES North Atlantic Special Issue.

Yucel, M., Gartman, A., Chan, C.S., Luther, G.W., 2011. Hydrothermal vents as a kinetically stable source of iron-sulphide-bearing nanoparticles to the ocean. Nature Geoscience 4, 367-371. 
(a) USGT11-11

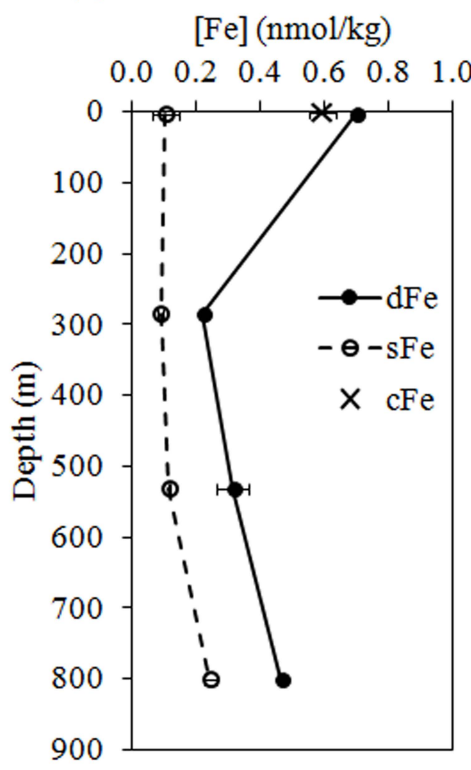

(b) $\delta^{56} \mathrm{Fe}(\%)$

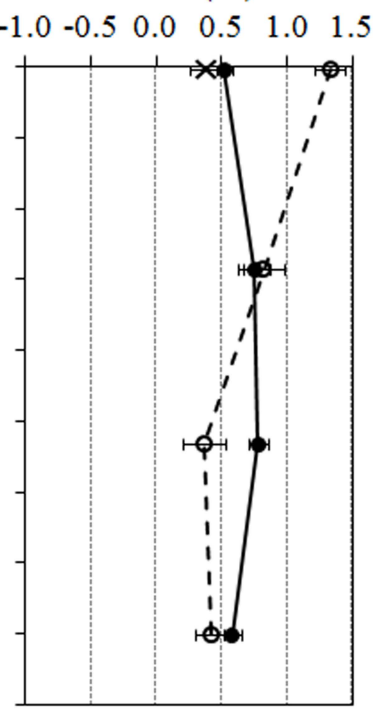

USGT11-21 and -23

$[\mathrm{Fe}](\mathrm{nmol} / \mathrm{kg}) \quad \delta^{56} \mathrm{Fe}(\%)$

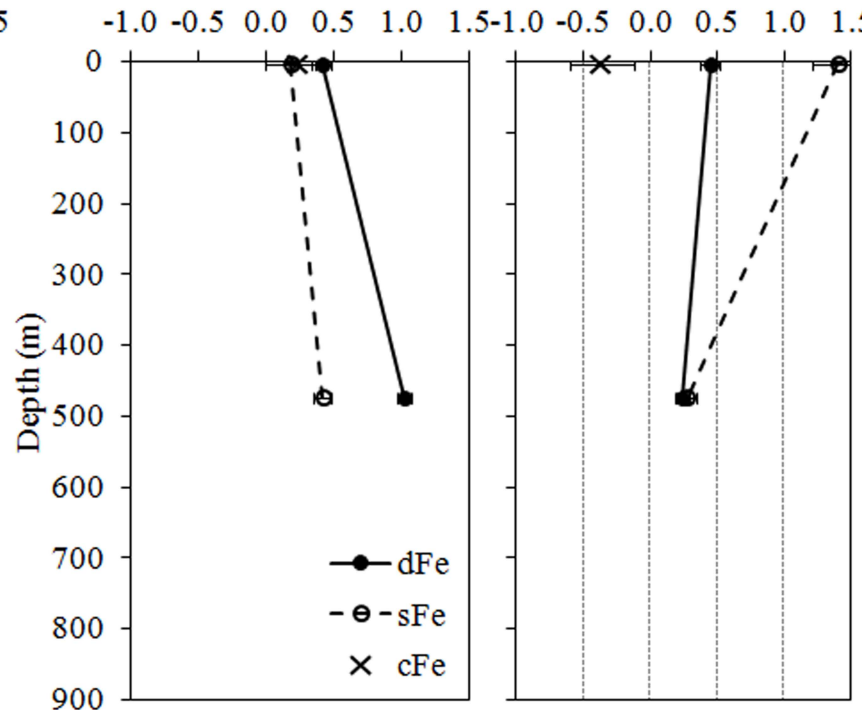


(a) Subsurface Ocean Fe Exchange Model: sFe and cFe cycle synchronously

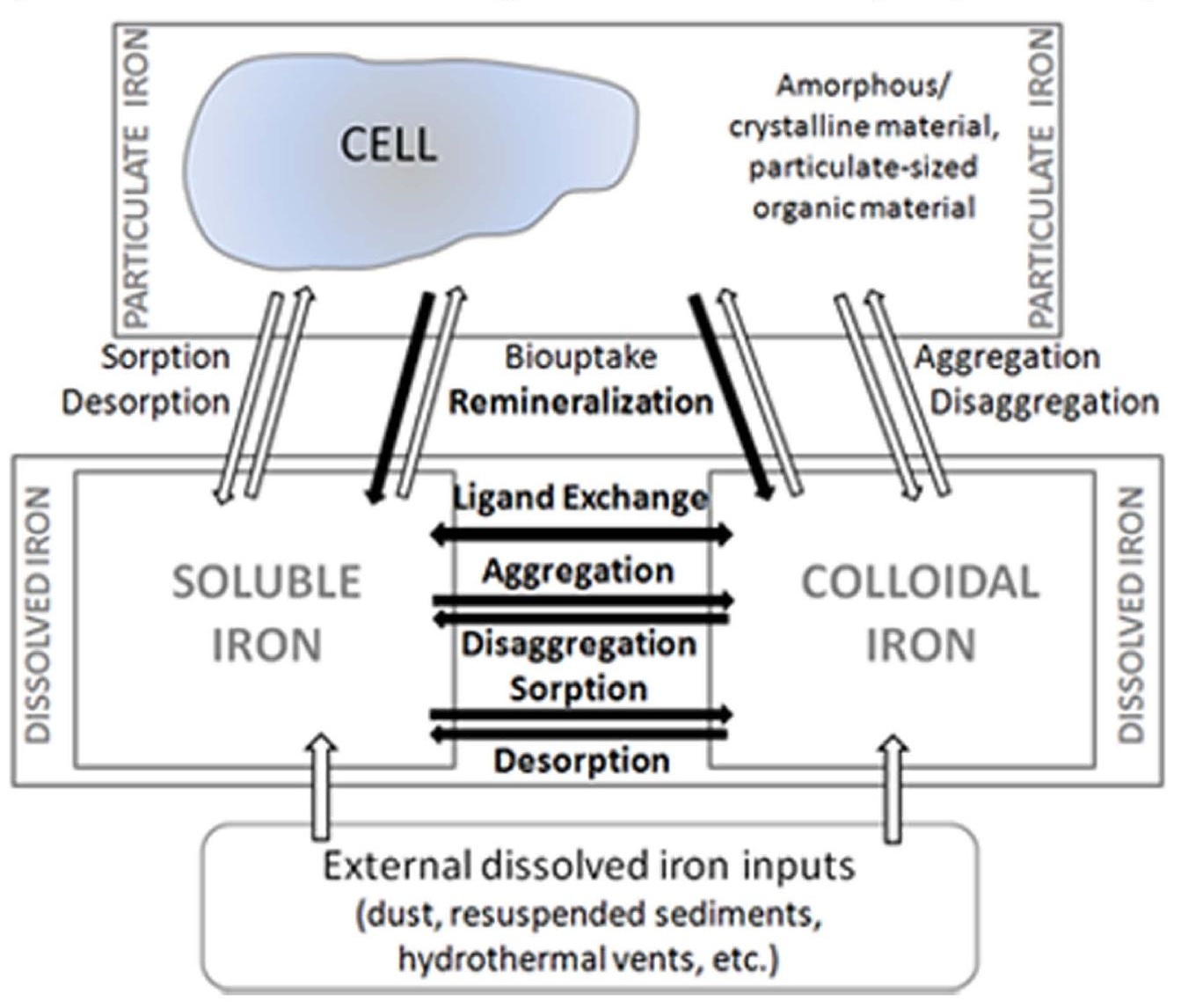

(b) Upper Ocean Fe Exchange Model: sFe and cFe cycle independently

(a) USGT11-14

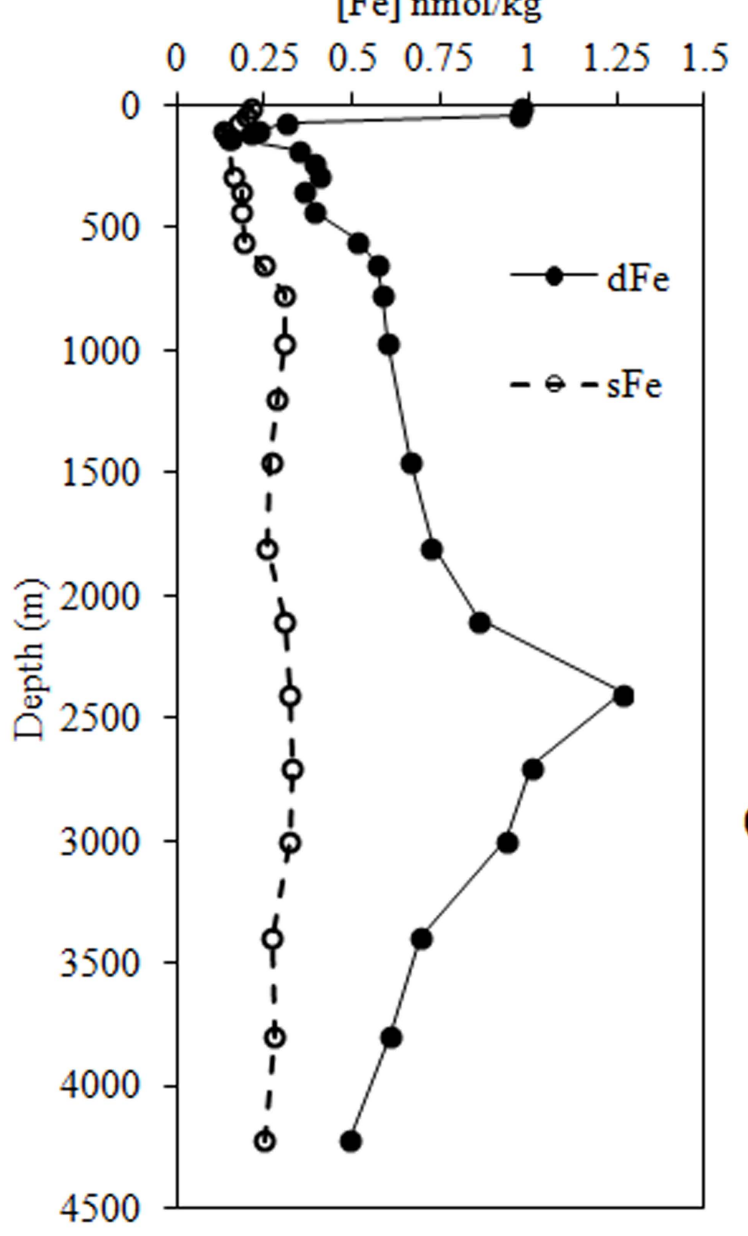

(b)

USGT11-16

$[\mathrm{Fe}] \mathrm{nmol} / \mathrm{kg}$

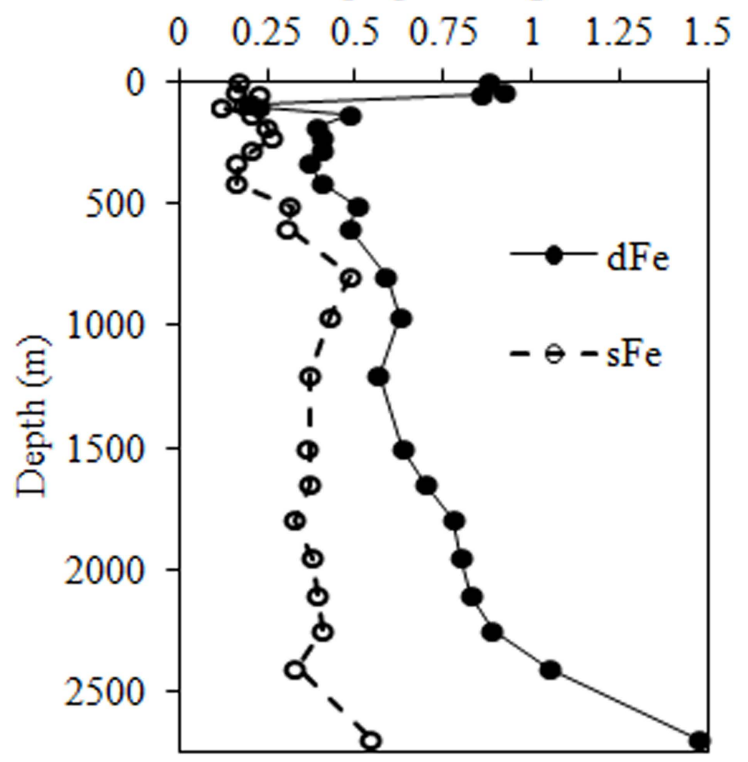

(c) 3000

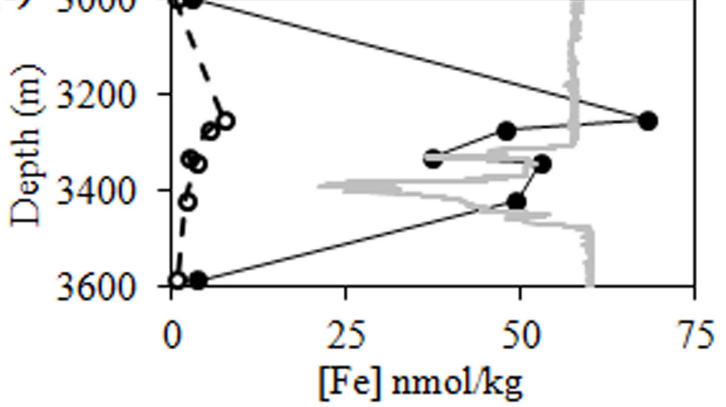




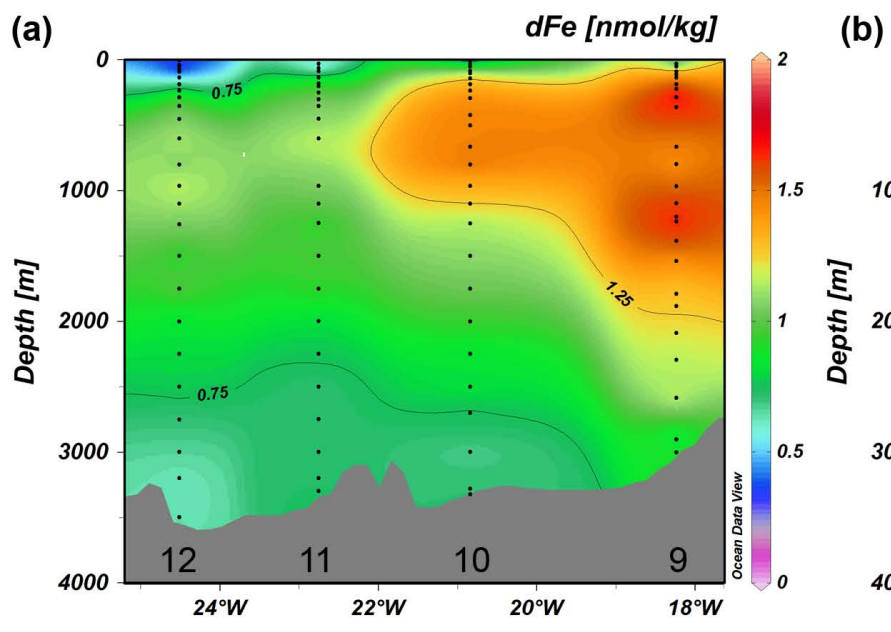

(c)

हิ

$\mathrm{cFe}[\mathrm{nmol} / \mathrm{kg}]$

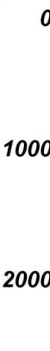

3000
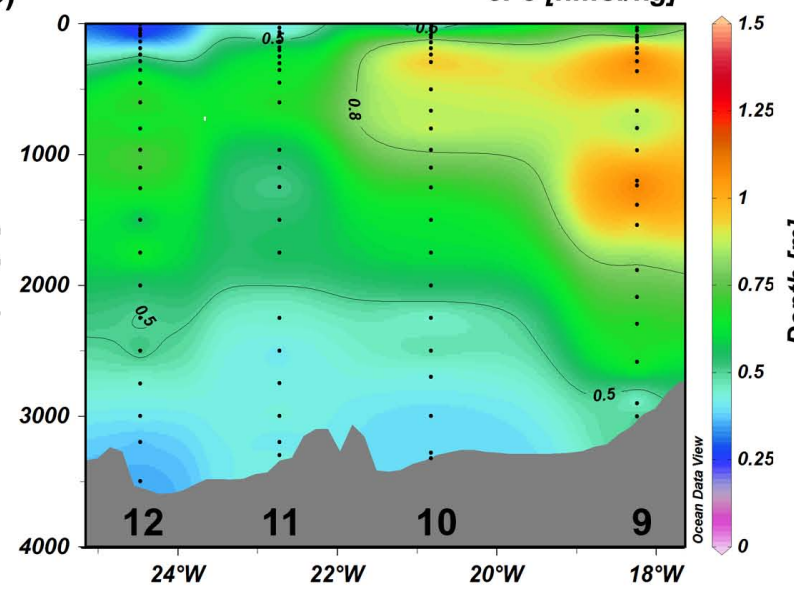

(b)

sFe $[\mathrm{nmol} / \mathrm{kg}]$

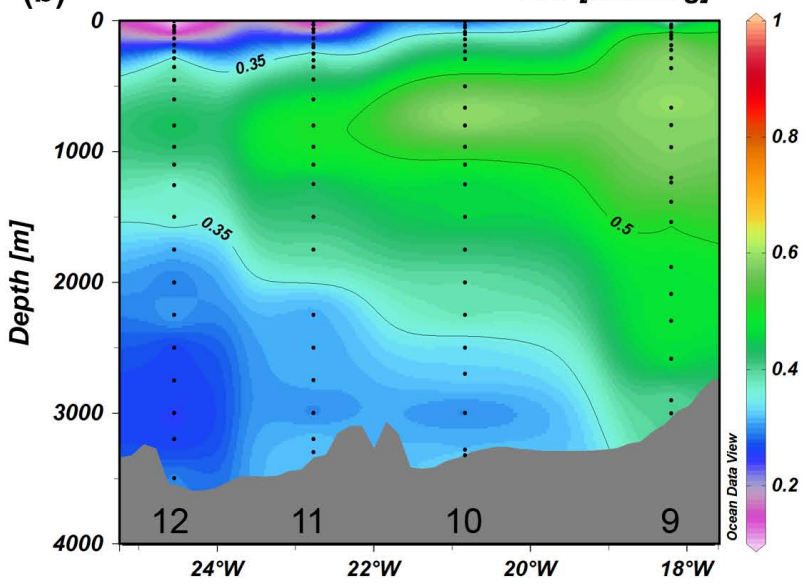

(d)

$\% c F e$
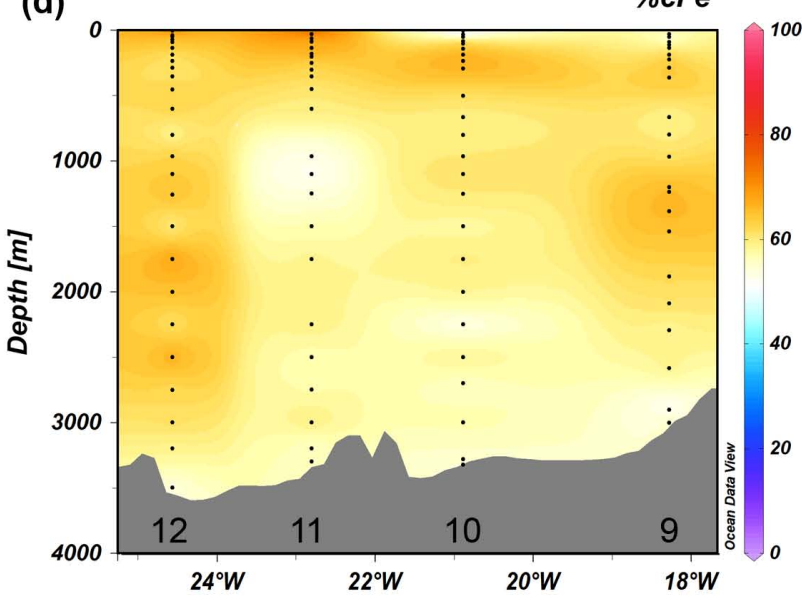
$\begin{array}{ll}\text { (a) } & \text { USGT11-06 } \\ & {[\mathrm{Fe}] \mathrm{nmol} / \mathrm{kg}}\end{array}$

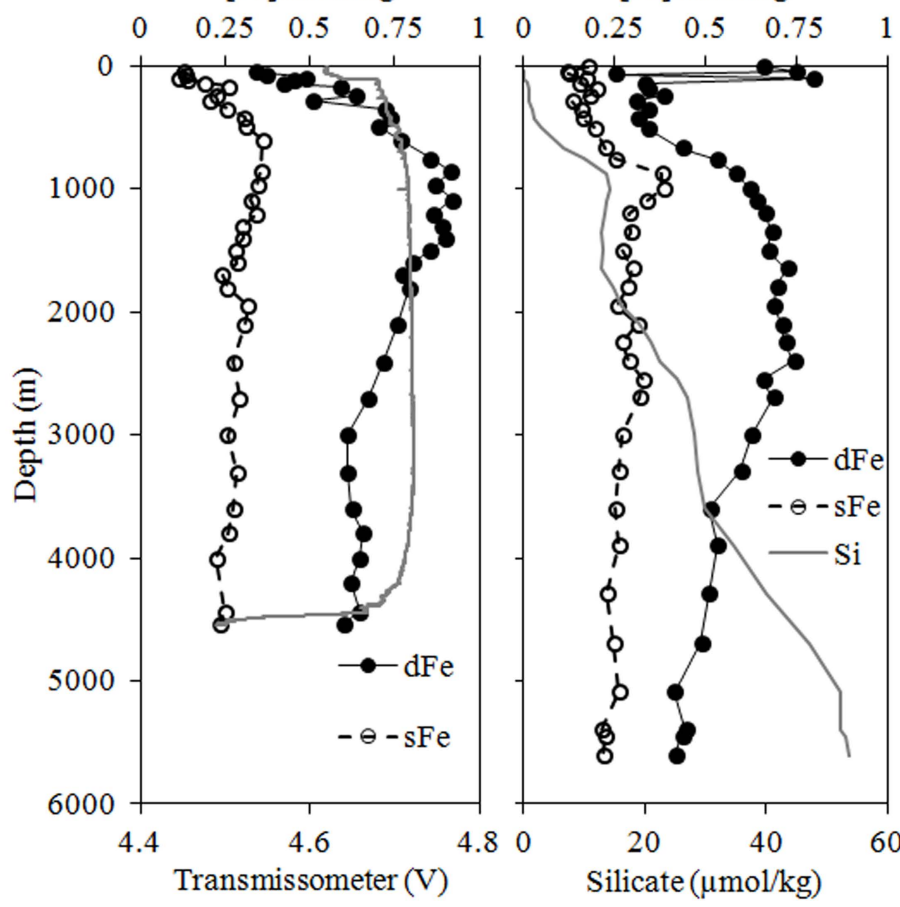

(c) USGT11-20

[Fe] nmol $/ \mathrm{kg}$

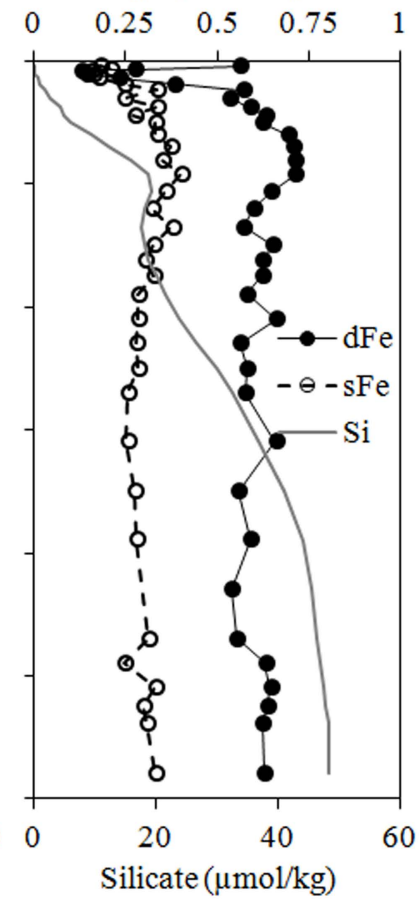

(d)

USGT10-09 $[\mathrm{Fe}] \mathrm{nmol} / \mathrm{kg}$

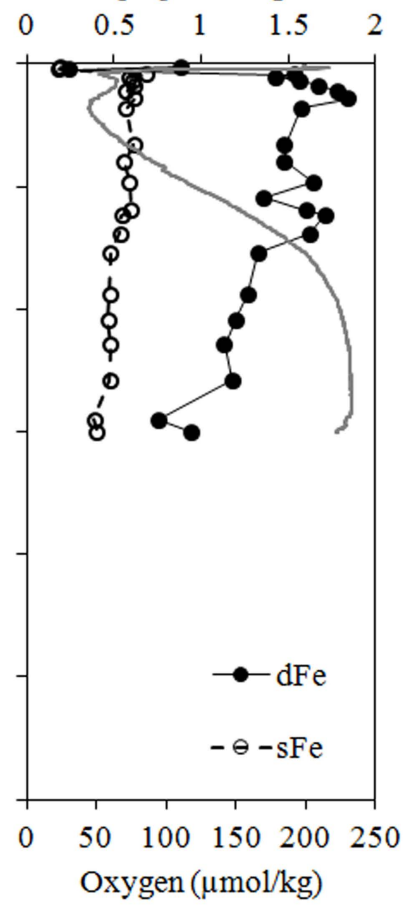




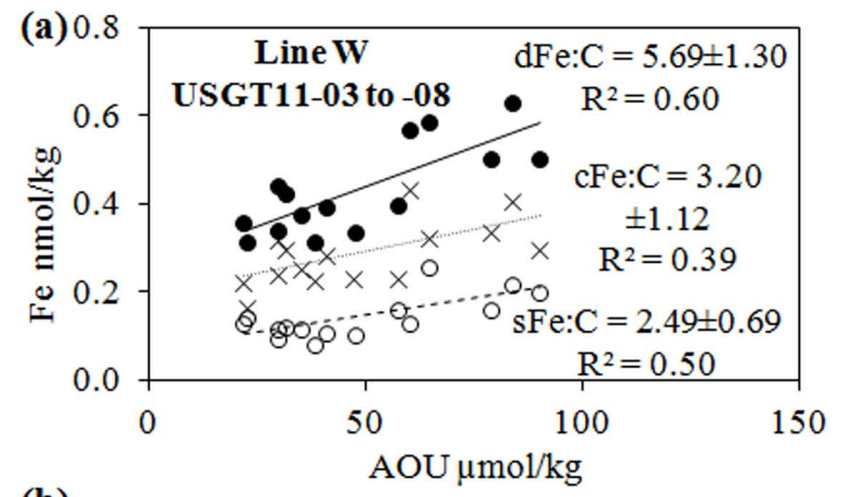

(b)

Line W $\mathrm{dFe}: \mathrm{C}=5.69 \pm 1.30$

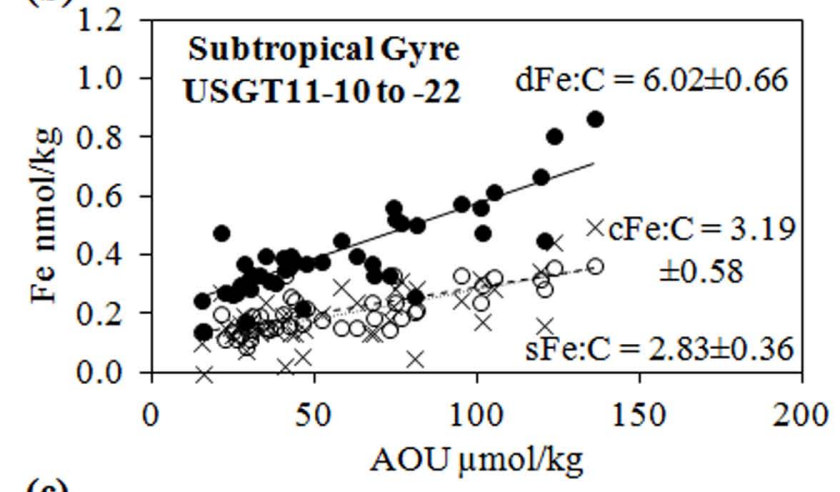

(c)




(a) USGT11-06

$\mathrm{Fe}(\mathrm{nmol} / \mathrm{kg})$ (b) USGT11-16 (TAG)

$\mathrm{Fe}(\mathrm{nmol} / \mathrm{kg})$ (c) USGT11-20

$\mathrm{Fe}(\mathrm{nmol} / \mathrm{kg})$

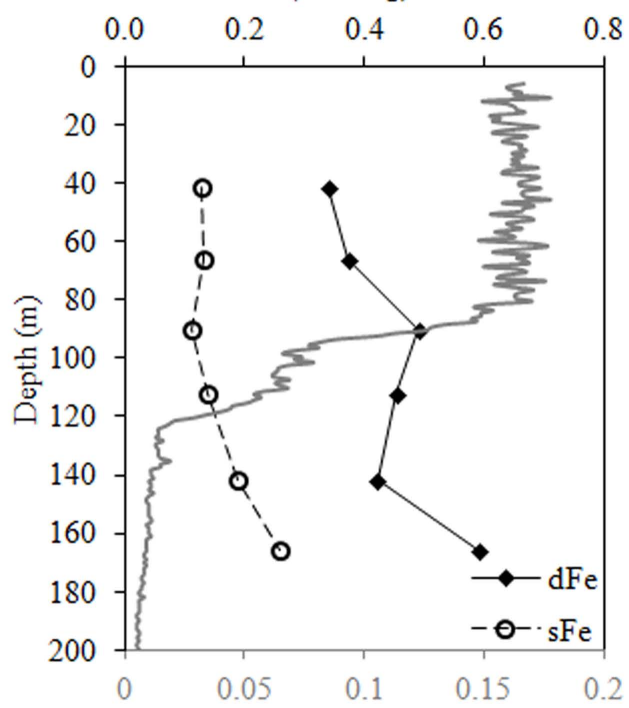

Fluorescence

(d) USGT10-05

$\mathrm{Fe}(\mathrm{nmol} / \mathrm{kg})$

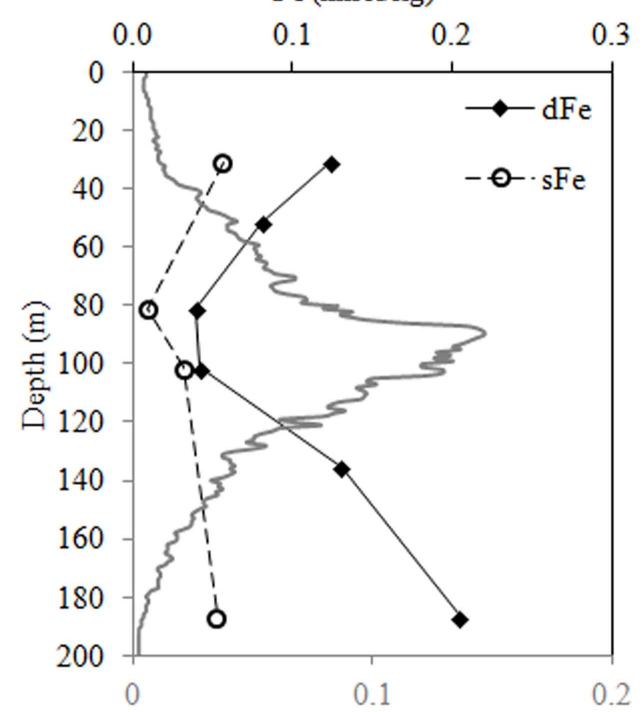

Fluorescence

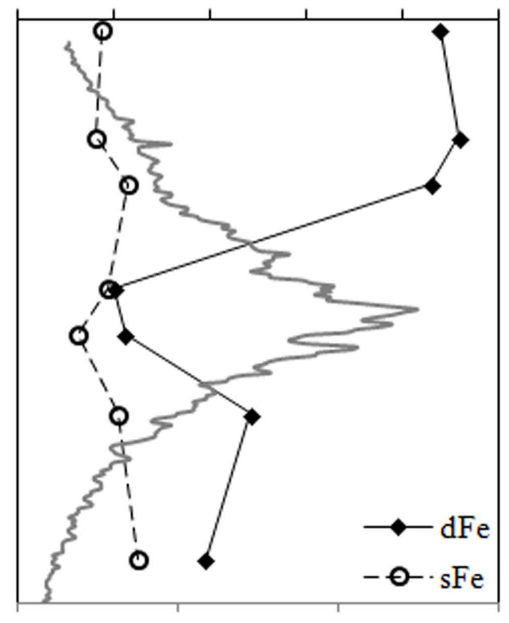

0


Fluorescence
(e) USGT10-09
$\mathrm{Fe}(\mathrm{nmol} / \mathrm{kg})$

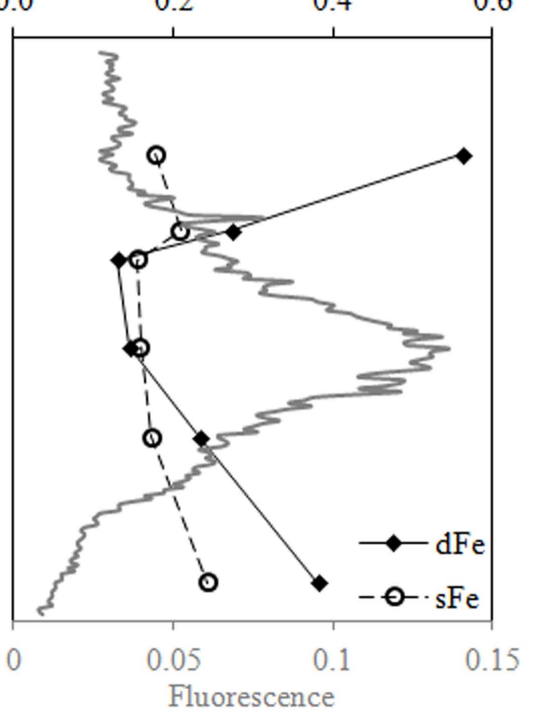

(f) USGT10-09

Transmissometry (V)

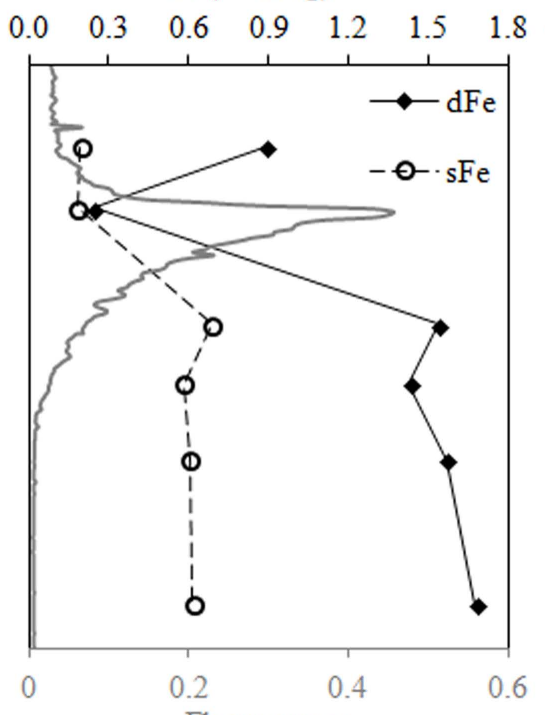

Fluorescence

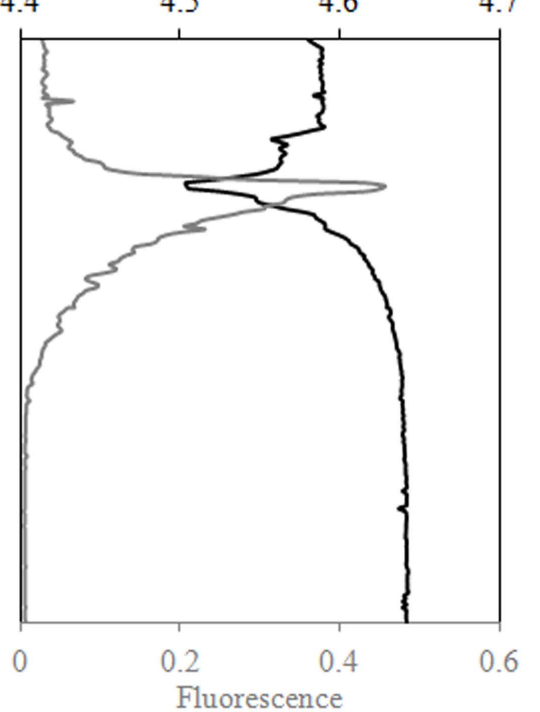




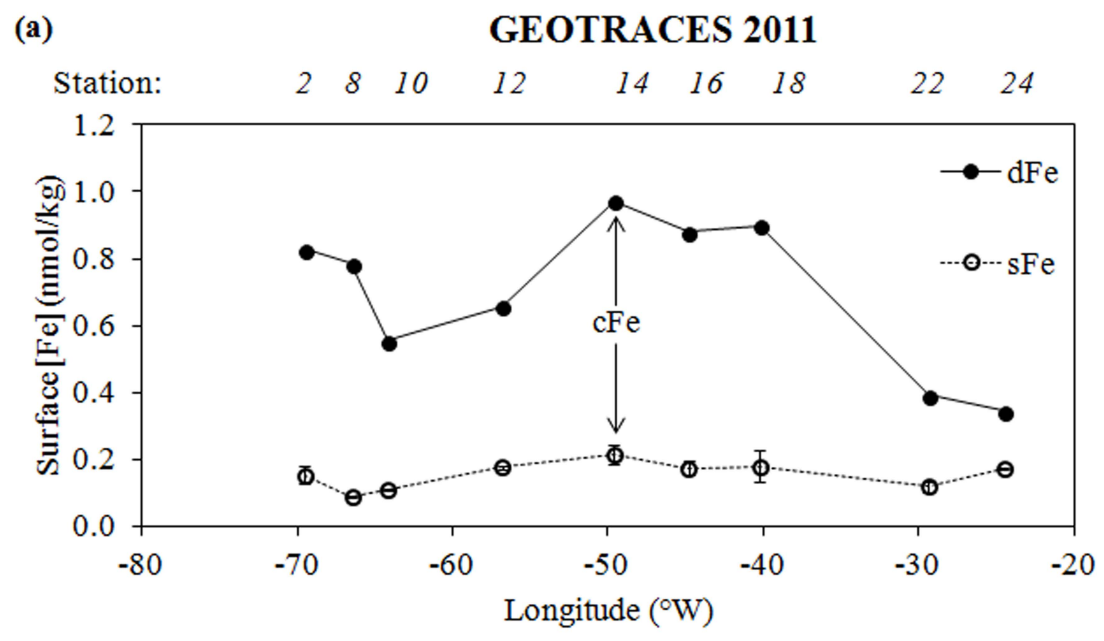

(b)

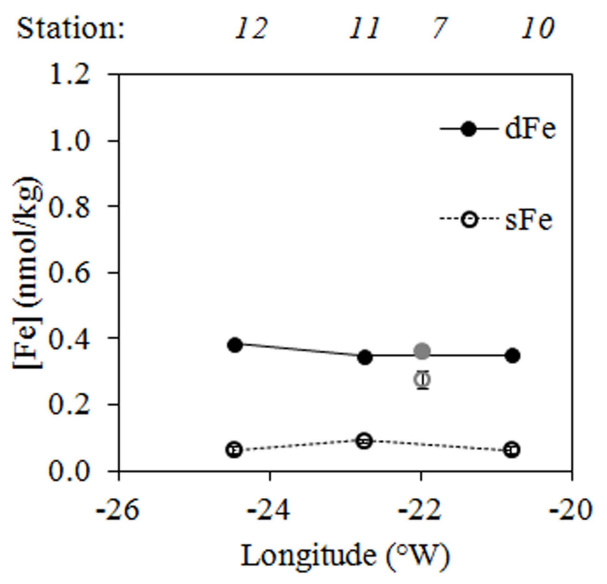


Fig. 1 Station map. Stations from the 2010 cruise are shown in red, and stations from the 2011 cruise are in blue. The TENATSO crossover station was occupied on both cruises (station USGT10-12 and station USGT11-24). The locations of the Line W stations (USGT11-02 through USGT11-08), BATS station (USGT11-10), TAG hydrothermal station (USGT11-16), and the Mauritanian transect (USGT10-09 through USGT10-12) are also indicated. Stations from the literature that are referenced in this paper are also indicated as open symbols (Bergquist et al., 2007; Fitzsimmons and Boyle, 2014b).

Fig. 2 Sections from the 2011 cruise of (a) dissolved $\mathrm{Fe}<0.2 \mu \mathrm{m}$ analyzed by the Mg coprecipitation method of $\mathrm{Wu}$ and Boyle (1998), (b) soluble $\mathrm{Fe}<0.02 \mu \mathrm{m}$ analyzed by the NTA method of Lee et al. (2011), (c) colloidal Fe calculated as dFe - sFe, and (d) \%cFe calculated as $\mathrm{cFe} / \mathrm{dFe}$ (in percent). Station numbers are shown at the bottom of each panel.

Fig. 3 Surface dFe partitioning as a function of longitude from (a) the 2011 cruise and (b) the 2010 cruise. Station numbers are indicated at the top. Colloidal Fe can be calculated as dFe minus sFe. Recall

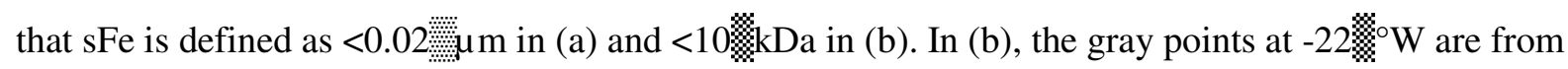
USGT10-07, which lies somewhat north of the other three stations indicated (Mauritanian transect USGT10-10 through USGT10-12). Error bars show \pm 1 standard deviation error on analytical replicates.

Fig. 4 The speciation and size distribution of dissolved Fe in the upper 200\% $\%$ on (a-c) the 2011 cruise where sFe is defined as $<0.02$ wiw $<10 \% \mathrm{kDa}$. The deep chlorophyll maximum (DCM) is designated as the fluorescence maximum in grey. Note that colloidal $\mathrm{Fe}$ (dFe minus $\mathrm{sFe}$ ) goes to zero at the DCM, except along the western North Atlantic margin (a: USGT11-06). Not surprisingly, the DCM also appears to be a depth of maximum particle loading at many stations, as the light transmission shows a coincident minimum with the DCM (f: USGT10-09, as an example).

Fig. $5 \mathrm{dFe}$ partitioning resulting from remineralization in the Central Water layer (potential density 25.8-27.1 $\mathrm{kg} / \mathrm{m}^{3}$ ), shown as a function of apparent oxygen utilization (AOU) for (a) Line W USGT1103 to -08 where the sFe size cutoff is 0.02 i: $\mu \mathrm{m}$, (b) the subtropical gyre stations USGT11-10 to -24 where the sFe size cutoff is 0.02 w size cutoff is $10 \% \mathrm{kDa}$. Samples are only utilized in these regressions if they are below the DCM and away from external Fe sources (margin and hydrothermal stations are removed). Filled circles show dFe

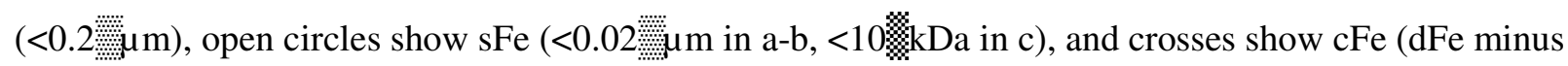
$\mathrm{sFe}$ ). Fe: $\mathrm{C}$ values (in units of $\mu \mathrm{mol} / \mathrm{mol}$ ) are calculated from the Type-I regressions shown using an 
AOU:C ratio of 1.6 (Martin et al., 1987). Errors are \pm 1 standard error from the calculated regression slope.

Fig. 6 Full-depth ocean profiles of dissolved $\mathrm{Fe}(<0.2$ 善 $\mathrm{Wm}$, closed circles $)$ and soluble Fe $(<0.02$. trace, (b) USGT11-12 with the silicate trace, (c) USGT11-20 with the silicate trace, and (d) USGT10-09 with the oxygen trace.

Fig. 7 Sections from the 2010 cruise along the Mauritanian transect of (a) dissolved $\mathrm{Fe}<0.2 \mu \mathrm{m}$, (b) soluble Fe $<0.02 \mu \mathrm{m}$, (c) colloidal Fe calculated as dFe-sFe, and (d) \%cFe calculated as cFe/dFe. Station numbers are shown at the bottom of each panel.

Fig. 8 A comparison of dFe size partitioning during the two years of cruises at TENATSO. (a) dFe $(<0.2$ wam) over the two years with the oxygen shown in gray to designate the OMZ. (b) sFe over the two years, with the 2010 sampling occurring by CFF $(<10 \% \mathrm{NDa})$ and the 2011 sampling occurring by Anopore filtration $(<0.02$ wiw sFe collected by CFF divided by the $2011 \mathrm{sFe}$ collected by Anopore filtration. Depths where this ratio is particularly low indicate depths where there is a significant component of $\mathrm{dFe}$ in the $10 \% \mathrm{kDa}-0.02 \mu \mathrm{m}$ size fraction. The dotted line at 70\% $\mathrm{m}$ is the DCM, and the shaded region includes depths where the dissolved oxygen concentration is $<100$ w्wi: $\mu \mathrm{mol} / \mathrm{kg}$ (the OMZ). Error bars indicate \pm 1 standard deviation in replicate analyses of the same sample.

Fig. 9 dFe size partitioning at (a) station USGT11-14, which is $\sim 500 \%$ km to the northwest of the TAG site, and (b-c) station USGT11-16, the TAG site (note the much larger dFe scale in panel c). Colloidal $\mathrm{Fe}(\mathrm{cFe})$ can be taken as the difference between $\mathrm{dFe}$ and $\mathrm{sFe}$ at any depth. In (c), the grey line shows the transmissometer trace, where a drop in the signal designates light absorption by enhanced particles in the water column. In the portion of the water column influenced by hydrothermal venting, sFe comprises $9-18 \%$ of the dFe at USGT11-14 compared to only $4-11 \%$ of the dFe at TAG USGT1116.

Fig. 10 Relationships between $\mathrm{dFe}, \mathrm{sFe}$, and cFe in (a) Bergquist et al. (2007), (b) Fitzsimmons and Boyle (2014b), (c) Line W stations USGT11-02 through USGT11-08, (d) North Atlantic subtropical gyre stations USGT11-10 through USGT11-22, and (e) stations USGT10-05 through USGT10-12 from the 2010 eastern North Atlantic cruise including the Mauritanian/OMZ section. In panels c-e, depths below the DCM are shown as filled circles and are included in the regressions, while depths at and 
above the DCM are shown as open circles and are not included in the regressions. Station USGT11-16 is excluded altogether, as are the TAG-influenced depths at Station USGT11-14. Regressions are TypeII, and in (a) the statistics are taken from Bergquist et al. (2007). The dashed line on the right panels shows the $1: 1 \mathrm{sFe}: \mathrm{cFe}$ line.

Fig. 11 Model of Fe size partitioning, focused on the processes controlling dFe partitioning into soluble and colloidal fractions (box size has no relation to relative Fe pool size in this figure) for (a) the subsurface ocean (below the deep chlorophyll maximum) and (b) the upper ocean (surface through the deep chlorophyll maximum). Measurable quantities are shown in the gray rectangles ( $\mathrm{sFe}, \mathrm{cFe}, \mathrm{dFe}$, $\mathrm{pFe}$ ), and exchange rates are shown as arrows. The black arrows and bolded processes indicate the mechanism(s) driving the dominant partitioning pattern expressed in the partitioning plots of Fig. 10 for each depth range.

Fig. 12 Size partitioned dFe concentration and stable isotope ratio $\left(\delta^{56} \mathrm{Fe}\right)$ at (a) USGT11-11 near Bermuda and (b) USGT11-21 (at the surface) and USGT11-23 (at 475\% $\mathrm{m}$ ). dFe $(<0.2$ ॠ. with filled circles and solid lines, $\mathrm{sFe}(<10 \% \mathrm{kDa})$ is shown with open circles and dashed lines, and $\mathrm{cFe}$ $(10 \% \mathrm{kDa}<\mathrm{cFe}<0.2$ win $)$ is shown as crosses and was calculated as $\mathrm{dFe}-\mathrm{sFe}$ and by isotope mass balance. The dissolved oxygen CTD trace is indicated in gray for USGT11-11 and USGT11-23.

Table 1 Reported procedure blanks, detection limits, and comprehensive lab analyses of the SAFe standard reference materials over the analytical sessions. dFe concentrations were analyzed in the Wu laboratory at RSMAS by the method described in Wu and Boyle (1998). sFe concentrations were analyzed in the Boyle laboratory at MIT by the methods described in Lee et al. (2011). All Fe concentrations are in units of $\mathrm{nmol} / \mathrm{kg}$, and consensus values are taken from http://www.geotraces.org/science/intercalibration as of May 2013. The detection limit is calculated as three times the standard deviation of the procedure blank for each analytical session.

\begin{tabular}{|c|c|c|c|c|}
\hline Parameter or SRM & Consensus [Fe] & [dFe] & $2010[\mathrm{sFe}]$ & 2011 [sFe] \\
\hline Procedure blank range & - & $\begin{array}{l}0.078 \pm 0.008 \\
\text { ( } n=11 \text { sessions) }\end{array}$ & $\begin{array}{l}0.009-0.019 \\
\text { ( } n=11 \text { sessions) }\end{array}$ & $\begin{array}{l}0.006-0.026 \\
\text { ( } n=18 \text { sessions) }\end{array}$ \\
\hline Detection limit $(3 \sigma)$ & - & $0.03-0.05$ & 0.027 & 0.030 \\
\hline SAFe D2 & $0.933 \pm 0.032$ & $0.950 \pm 0.035$ & $\begin{array}{l}0.931 \pm 0.046 \\
(\# 446, n=28)\end{array}$ & $\begin{array}{l}0.930 \pm 0.042 \\
(\# 446, n=43)\end{array}$ \\
\hline $\begin{array}{l}\text { SAFe surface underway } \\
\text { (Boyle-lab internal standard) }\end{array}$ & $\begin{array}{l}0.093 \pm 0.008 \\
\text { (assume SAFe S) }\end{array}$ & - & $\begin{array}{l}0.083 \pm 0.035 \\
(n=39)\end{array}$ & $\begin{array}{l}0.079 \pm 0.050 \\
(n=73)\end{array}$ \\
\hline SAFe S & $0.093 \pm 0.008$ & $0.103 \pm 0.010$ & - & $\begin{array}{l}0.094 \pm 0.006 \\
(\# 16, n=3) \\
0.108 \pm 0.002 \\
(\# 318, n=3)\end{array}$ \\
\hline
\end{tabular}


Table $2 \mathrm{dFe}: \mathrm{C}$ and $\mathrm{sFe}: \mathrm{C}$ relationships (in $\mu \mathrm{mol} / \mathrm{mol}$ ) and pre-formed $\mathrm{dFe}$ and $\mathrm{sFe}$ (in $\mathrm{nmol} / \mathrm{kg}$ ) Central Waters below the DCM in the potential density range $25.8-27.1$ illantic $\mathrm{kg} / \mathrm{m}^{3}$ (largely dominated by North Atlan Water, with smaller contributions of Atlantic Equatorial Water, and Southwest Atlantic Central Water, Jenkins et al., this issue). The $\% \mathrm{sFe}_{\text {REMIN }}$ (\% soluble Fe attributed to remineralization) is calculated as the ratio of sFe:C to dFe:C (ignores the partitioning contribution by pre-formed $\mathrm{dFe}$ ). The $\% \mathrm{sFe}_{\mathrm{PF}}$ attributed to pre-formed $\mathrm{dFe}$ is calculated as the ratio of pre-formed $\mathrm{sFe}$ to pre-formed $\mathrm{dFe}$ (ignores the partitioning contribution by remineralization). $\mathrm{Fe}: \mathrm{C}$ values are calculated from a Type-I regression of Fe and AOU, and the Fe:AOU slope was converted to an Fe:C using the AOU:C ratio of 1.6 (Martin et al., 1987). Error values are \pm 1 standard error from the calculated regression.

\section{Year Stations Dissolved Fe dFe:C ( $\mu \mathrm{mol} / \mathrm{mol}$ )}

2010

$7,11,12$

$5.49 \pm 0.82$

2011

$5.69 \pm 1.30$

8

Gyre: 10-

22

Soluble Fe (nmol/kg)

$0.45 \pm 0.08$

$0.26 \pm 0.04$

$0.20 \pm 0.03$
$\%$ sFe REMIN

sFe:C

( $\mu \mathrm{mol} / \mathrm{mol}$ )

$6.02 \pm 0.66$
$2.26 \pm 1.06$

$2.49 \pm 0.69$
$2.83 \pm 0.36$
$\% \mathrm{sFe}_{\mathrm{PF}}$

Pre-

formed

sFe

(nmol/kg)

$0.16 \pm 0.10 \quad 41 \pm 25 \% \quad 35 \pm 29 \%$ $0.07 \pm 0.02 \quad 44 \pm 22 \% \quad 27 \pm 13 \%$ $0.11 \pm 0.01 \quad 47 \pm 11 \% \quad 57 \pm 15 \%$
sFe:C / PredFe:C formed $\mathrm{sFe} / \mathrm{dFe}$ 